\title{
Discrimination of Mature and Dissipating Severe-Wind-Producing MCSs with Layer-Lifting Indices
}

\author{
Diego A. Alfaro \\ Universidad Nacional Autónoma de México, Mexico City, Mexico \\ MiCHAEL C. CONIGLIO \\ NOAA/OAR/National Severe Storms Laboratory, Norman, Oklahoma
}

(Manuscript received 29 June 2017, in final form 16 October 2017)

\begin{abstract}
The environmental factors that drive the dissipation of linear severe-wind-producing mesoscale convective systems (MCSs) are investigated. Layer-lifting indices are emphasized, which measure convective instability in forward-propagating MCSs by considering that deep convective latent heating depends on 1) the potential latent heating within the atmospheric column, measured by the integrated CAPE (ICAPE), and 2) the dilution of buoyancy due to midtropospheric inflow, measured by the inflow fraction (IF) of convectively unstable air to total system-relative inflow. These elements are integrated to define the layer-lifting CAPE $\left(\mathrm{CAPE}_{\mathrm{ll}}\right)$, which depends on environmental thermodynamics, kinematics, and the MCS's movement vector. Radar reflectivity plots are used to subjectively identify and classify MCSs in terms of their stage (mature or dissipating) and degree of organization (highly or weakly organized). Nonparametric statistical inferences are performed on several metrics computed at maturity and dissipation from RUC/RAP analysis data, aiming to identify the most skillful indices for diagnosing three different aspects of MCS dissipation: 1) the transition from maturity to dissipation, 2) the stage of an MCS, and 3) the disorganization that characterizes the dissipating stage. In terms of MCS dissipation CAPE $\mathrm{Cl}_{\mathrm{l}}$ is the best diagnostic. A close approximation to CAPE is accomplished by estimating an MCS's movement with Corfidi vectors, providing a potentially useful index in operational settings. ICAPE is the most skillful thermodynamic metric, while IF is the best kinematic discriminator of MCS stage and stage transition, suggesting the fundamental importance of layer-lifting convective instability for MCS maintenance. Layer-lifting indices are not particularly skillful at distinguishing the degree of MCS organization at maturity, which is best diagnosed by deep vertical wind shear.
\end{abstract}

\section{Introduction}

Deep convection in the continental United States often is organized into mesoscale convective systems (MCS; Houze 2004), storms that generate a significant fraction of the accumulated warm-season precipitation (Fritsch et al. 1986; Jirak et al. 2003), sometimes producing floods (Maddox et al. 1979; Doswell et al. 1996; Schumacher and Johnson 2005) and severe weather (Johns and Hirt 1987; Ashley and Mote 2005). Hence, it is important to develop effective forecasting tools (e.g., Coniglio et al. 2007, hereafter CBWC) and precise representations in coarse-resolution numerical models (Moncrieff 2010) of MCSs and their associated impacts.

Corresponding author: Diego Alfaro, diego.alfaro@atmosfera. unam.mx
These tasks require the identification of environments supportive of MCS organization (Bluestein and Jain 1985; Parker and Johnson 2000; Coniglio et al. 2004; Jirak and Cotton 2007; Schumacher and Johnson 2009), intensity (Cohen et al. 2007; Corfidi et al. 2016), and maintenance (Gale et al. 2002; CBWC; Coniglio et al. 2010; Letkewicz and Parker 2010), a problem that remains challenging. It is unlikely that such difficulties arise exclusively from the intrinsic predictability limitations inherent to MCSs (Wandishin et al. 2010; Melhauser and Zhang 2012; Nielsen and Schumacher 2016; Durran and Weyn 2016; Weyn and Durran 2017), given that our theoretical understanding of the dependence of MCS morphology on the embedding environment remains incomplete. Below, we elaborate further on this matter, hereafter focusing on quasi-linear organized storms. 
Ideally, efforts to forecast and diagnose MCS features should be guided by rigorous and observationally validated theory. But despite many advances in our understanding of MCS dynamics in relation to environmental vertical wind shear (Thorpe et al. 1982; Rotunno et al. 1988; Coniglio et al. 2006; among others) and convective instability (Nicholls et al. 1988; Weisman 1992, 1993; Takemi 2006; among others), it has been difficult to apply those results to produce robust metrics for operational use. ${ }^{1}$ For instance, traditional convective instability indices (e.g., CAPE) do not appear to represent a strong constraint on the severity of observed MCSs (Evans and Doswell 2001; Cohen et al. 2007). With regard to environmental kinematics, a notable example is Rotunno et al.'s (1988) theory of vorticity balance (hereafter RKW theory), which proposes that the morphology of linear MCSs depends mainly on the strength of the vertical wind shear in relation to the intensity of the evaporatively driven cold pool. While RKW theory has been successfully applied in idealized simulated MCSs (e.g., Weisman et al. 1988; Weisman 1992, 1992; Weisman and Rotunno 2004; Bryan et al. 2006), a strict application of the theory in operations is difficult, both because of observational limitations in relation to cold pool intensity measurements (Corfidi 2003; Bryan et al. 2005) and due to a lack of observational evidence for stronger MCS modes (e.g., Evans and Doswell 2001; Gale et al. 2002; Stensrud et al. 2005; Coniglio et al. 2012). Within this context of inconsistent correspondence between theory and observations, approaches to design metrics for operational applications (e.g., severe weather nowcasting) incorporating both thermodynamic and kinematic features have relied mainly on statistical analysis (e.g., CBWC).

Recently, a layer-lifting formulation of convective instability in forward-propagating MCSs (Corfidi 2003) has been developed by Alfaro and Khairoutdinov (2015, hereafter AK) and Alfaro (2017, hereafter A17), which includes thermodynamic and kinematic impacts on latent heating. This layer-lifting framework has proven effective for diagnosing the intensity of several features in idealized MCSs, while also providing plausible explanations for the diagnostic limitations of CAPE and RKW theory. More specifically, AK argue that CAPE computed from a single parcel [e.g., surface based, most unstable, or mixed layer; see Bunkers et al. (2002)] fails to capture the bulk latent heating produced by the layer-

\footnotetext{
${ }^{1}$ Here, convective instability refers to nonzero CAPE, that is, latent instability, per the nomenclature in Schultz and Schumacher (1999), from a parcel-theory perspective.
}

lifting ascent at the leading edge of MCSs (e.g., Bryan and Fritsch 2000; Mechem et al. 2002). The authors propose integrated CAPE (ICAPE; see Mapes 1993) as a more appropriate measure of convective instability, because it contemplates latent heating by all unstable parcels. Building on ICAPE, A17 define the layer-lifting CAPE $\left(\mathrm{CAPE}_{11}\right)$ by incorporating the impacts of the inflow structure, whereby the latent heating is assumed to be modulated by the inflowing convectively unstable air as a fraction of total storm-relative inflow. Remarkably, $\mathrm{CAPE}_{11}$ explained most of the structural variability among the storms simulated by A17, leading to the conclusion that convective instability under layer-lifting ascent is a primary factor in determining the structure of mature, forward-propagating MCSs. On the other hand, A17 found that RKW metrics could not account for some large differences in MCS structures in various thermodynamic environments, perhaps explaining the lack of robust observational support for RKW theory in some MCS environments.

The successful application of the layer-lifting framework in idealized MCS simulations motivates this observational study, which is devoted to analyzing the relevance of layer-lifting indices, for example, ICAPE and $\mathrm{CAPE}_{\mathrm{ll}}$, for the maintenance of severe MCSs (Gale et al. 2002; CBWC; Coniglio et al. 2010; Letkewicz and Parker 2010). Our objective is twofold: first and foremost, we seek to validate the layer-lifting framework with observations and, second, we aim to produce metrics that might be useful in forecasting applications. To do so, we follow the approach of CBWC, wherein nonparametric statistical analyses are performed on a wide variety of metrics. An important difference with CBWC is that, instead of considering proximity soundings, analysis data from the Rapid Update Cycle (RUC; Benjamin et al. 2004) and Rapid Refresh (RAP: Benjamin et al. 2016) models are used for index computations, drastically lessening the spatiotemporal constraints due to sparse rawinsonde measurements. It is worth mentioning that the only storm-dependent parameter affecting $\mathrm{CAPE}_{11}$ is the system movement vector (MV), which can be easily estimated with radar reflectivity observations, implying that layer-lifting indices are well suited for the methods proposed herein.

The outline of this paper is as follows. Background on the layer-lifting framework is presented in section 2 . The methodology is established in section 3, detailing how radar imagery is used to identify and classify MCSs, specifying metric computations from RUC/RAP analysis data, and briefly describing the application of nonparametric statistical inferences to evaluate index performance. Section 4 presents results pertaining to metric changes from maturity to dissipation, followed by 


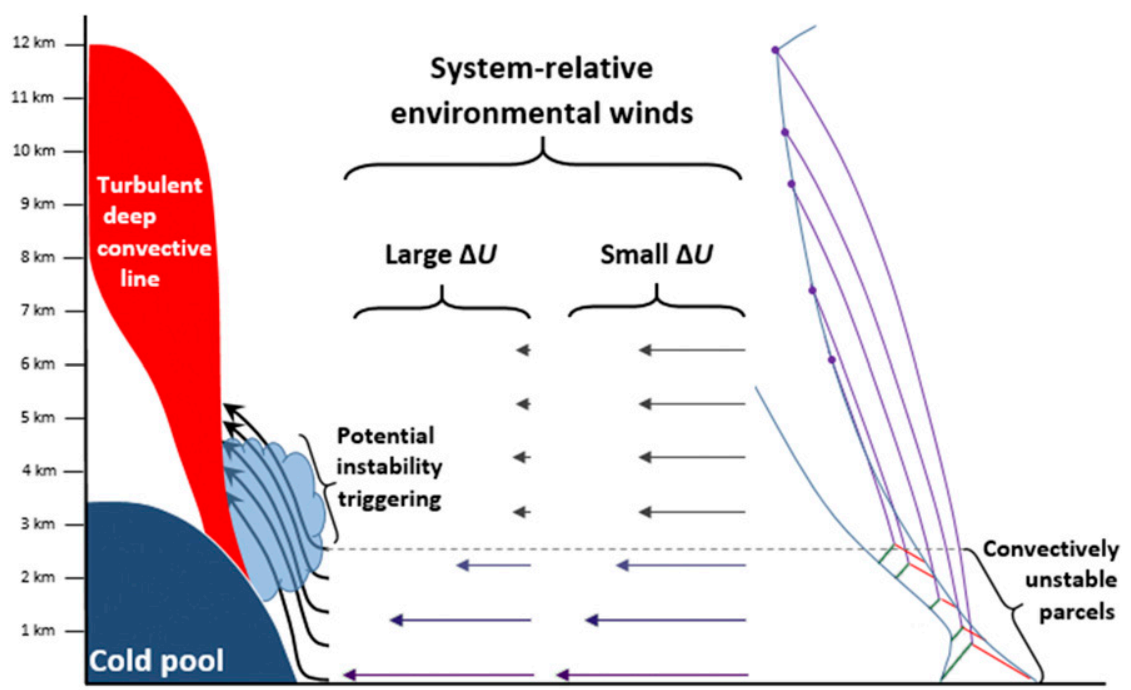

FIG. 1. Schematic illustration of relevant processes to layer-lifting convection. On the left, the layer-lifting ascent produced by an MCS's cold pool is displayed on a plane perpendicular to the deep convective line. On the right, a thermodynamic sounding is represented on a skew $T-\log p$ chart, displaying undiluted latent heating by ascending parcels originating at different levels. In the center, two different system-relative wind profiles are shown, where darker purple represents greater CAPE, while gray denotes stable air with relatively low $\theta_{e}$. (From A17.)

an assessment of the ability of indices to discriminate between mature and dissipating MCSs in section 5. Section 6 explores the relation between metrics and system disorganization during the dissipating stage through the skill of indices as discriminators between organization categories. In section 7, two simple examples pertaining to MCS stage forecasting are used to illustrate how results from nonparametric statistical analyses can be interpreted for practical applications. Section 8 defines and evaluates an operational version of $\mathrm{CAPE}_{11}$ using Corfidi vectors. A summary and discussion are presented in section 9 .

\section{Background on layer-lifting indices}

It is well known that deep convection in many MCSs (e.g., those that develop intense cold pools) manifests through the lifting of thick layers of low- to midtropospheric air (Bryan and Fritsch 2000; Mechem et al. 2002; AK), as depicted schematically in Fig. 1. Layer-lifting convection is implicit in observational studies, showing that deep layers of air flow toward the leading edge of many MCSs (Kingsmill and Houze 1999; Evans and Doswell 2001; Gale et al. 2002; Coniglio et al. 2004; Cohen et al. 2007; Campbell et al. 2017, hereafter C17). The essence of the layer-lifting framework is to incorporate these features into the formulation of convective instability metrics using parcel-theory concepts (see A17 for more details).
An important feature to consider in layer-lifting systems is the dependence of the amount of latent heating within the deep convective region on the convective instability of all parcels in the atmospheric column (see Fig. 1). With CAPE $(z)$ being a measure of the convective instability of a parcel originating at height $z$, the bulk potential for latent heating in the atmospheric column can be measured with ICAPE (see AK):

$$
\operatorname{ICAPE}=\int \rho \operatorname{CAPE}(z) d z
$$

where the integral is taken over the entire troposphere.

It is also necessary to incorporate the effects of inflowing air, which are determined by the systemrelative line-normal winds ahead of the MCS. These effects are illustrated by the system-relative wind profiles displayed in Fig. 1, wherein the profile on the left corresponds to a more strongly sheared environment than the one on the right. Noting that both cases have inflow at all levels, it is reasonable to expect that the weakly sheared environment should produce greater inflow of low- $\theta_{e}$ midlevel air (gray arrows in Fig. 1), leading to more dilution of buoyancy within the updraft. More specifically, the rate of latent heating in the deep convective region will depend on the amount of inflowing convectively unstable air (purple arrows) as a fraction of the total storm-relative inflow. These effects are well accounted for by $\mathrm{CAPE}_{11}$ (see A17): 


$$
\begin{aligned}
\mathrm{CAPE}_{11}= & {\left[\int \rho \max \left(0, \mathrm{SS}-u_{\mathrm{env}}\right) \mathrm{CAPE} d z\right] } \\
& \times\left[\int \rho \max \left(0, \mathrm{SS}-u_{\mathrm{env}}\right) d z\right]^{-1}
\end{aligned}
$$

where $u_{\text {env }}$ are the line-normal environmental wind velocities [negative (positive) if blowing toward (away) from the system], and SS is the system's speed relative to the ground. Integrals extend from the surface to the level up to which dilution of buoyancy in the updraft due to inflowing air is considered relevant (e.g., $9 \mathrm{~km})$. Note that $\mathrm{SS}-u_{\mathrm{env}}$ gives the system-relative winds, positive (negative) for inflow (outflow), so CAPE $\mathrm{E}_{\mathrm{ll}}$ can be interpreted as an inflow-fraction weighted average of CAPE.

In $\mathrm{A} 17, \mathrm{CAPE}_{11}$ is conveniently approximated by an expression proportional to ICAPE:

$$
\begin{aligned}
\mathrm{CAPE}_{11} \approx & \alpha \operatorname{ICAPE}\left\{\left[\int_{\mathrm{CUL}} \rho \max \left(0, \mathrm{SS}-u_{\mathrm{env}}\right) d z\right]\right. \\
& \left.\times\left[\int \rho \max \left(0, \mathrm{SS}-u_{\mathrm{env}}\right) d z\right]^{-1}\right\}
\end{aligned}
$$

where CUL represents the convectively unstable layer, the integral with unspecified bounds comprises the layer considered in Eq. (2), $\alpha$ depends on the mass within the CUL, and the term in braces corresponds to the inflow fraction of convectively unstable air. The usefulness of Eq. (3) is in that it separates the thermodynamic effects and the impact of the inflow structure.

To gauge the relevance of system-relative inflow, inflow-fraction metrics for surface-based layers are defined as follows:

$$
\begin{aligned}
\mathrm{IF}_{z}= & {\left[\int_{0}^{z} \rho \max \left(0, \mathrm{SS}-u_{\mathrm{env}}\right) d z^{\prime}\right] } \\
& \times\left[\int \rho \max \left(0, \mathrm{SS}-u_{\mathrm{env}}\right) d z^{\prime}\right]^{-1},
\end{aligned}
$$

where $z$ is the thickness of the layer relative to which the inflow fraction is computed. Considering the approximation in Eq. (3), $\alpha\left(\mathrm{ICAPE} \times \mathrm{IF}_{3}\right)$ could also provide a reasonable approximation to $\mathrm{CAPE}_{11}$, given that the bulk of the convectively unstable air resides within the lowermost $3 \mathrm{~km}$. Thus, IF indices measure the dilution of buoyancy in the deep convective region due to inflowing air.

\section{Methodology}

\section{a. Selection and categorization of events}

The list of MCSs used in this study constitutes a subset of events considered by Corfidi et al. (2016) and C17, consisting of warm-season (May-August) systems observed between 2010 and 2014 over the continental United States. MCSs were identified by associating long swaths of severe-wind reports, obtained from the Storm Prediction Center database, to meso- $\alpha$-scale systems (Orlanski 1975) that appeared as forward propagating and quasi-linearly organized on the National Radar Reflectivity Mosaic of the National Centers for Environmental Information (NCEI 2017; see C17 for more details on case selection). This procedure for event identification excludes nonsevere storms, so the results presented herein might not be valid for other MCS types [e.g., the slow-moving extreme-rain-producing systems studied by Schumacher and Johnson (2005)]. Additionally, to be considered in this study, MCSs must comply with the following specifications:

- No widespread disruption by convection ahead of the system at dissipation is observed (i.e., the dissipation of an MCS is related to the background environment and not direct interaction with other convection).

- Dissipation must have occurred over land.

- No apparent strong external forcing from cold fronts is observed.

- No loosely organized multicell lines without stratiform precipitation are present.

- Only the forward-propagating part of the MCS is considered.

A total of 131 MCSs met the criteria specified above. For each system, the beginning of the mature stage is defined as the time at which systems attain a nearly contiguous line of high radar reflectivities and a well-defined stratiform region, as shown in Fig. 2b. At the time depicted in Fig. 2a the MCS is not considered mature because the stratiform region is still developing in the forward-propagating region, indicated by the oval. Dissipation is considered to initiate when the intensity of radar reflectivities within the deep convective region and the extent of the stratiformprecipitation area first decrease noticeably, as shown in Fig. 2d (cf. Fig. 2c), without there being subsequent system reinvigoration. The MV corresponds to the MCS's movement throughout maturity, which is determined by the vector joining the central point within the arch/line of high reflectivity at the start of the mature stage and its analog at the beginning of the dissipating stage (see Fig. 2). Visual inspection of radar reflectivity plots suggests that the assumption of system movement along a straight line, implicit in using MV throughout the mature stage, is a good approximation for the forward-propagating MCSs under consideration. The magnitude of MV and the duration of the mature stage determine SS. Figure 3 shows the 
a)

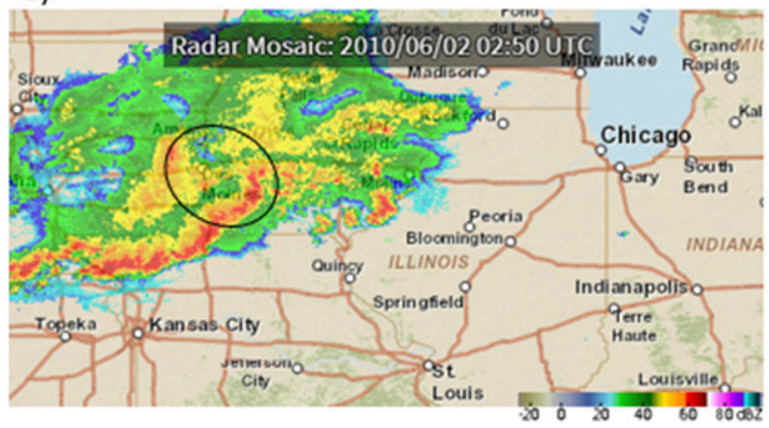

c)

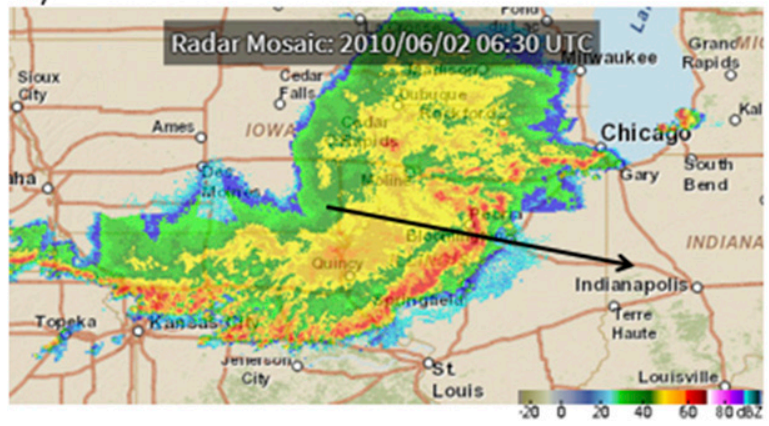

b)

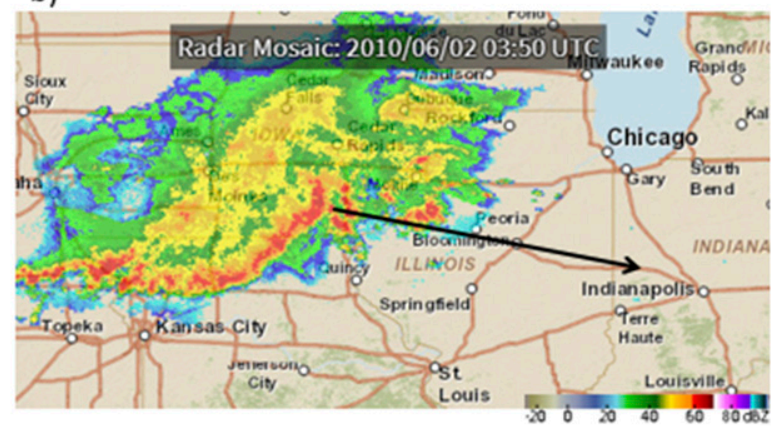

d)

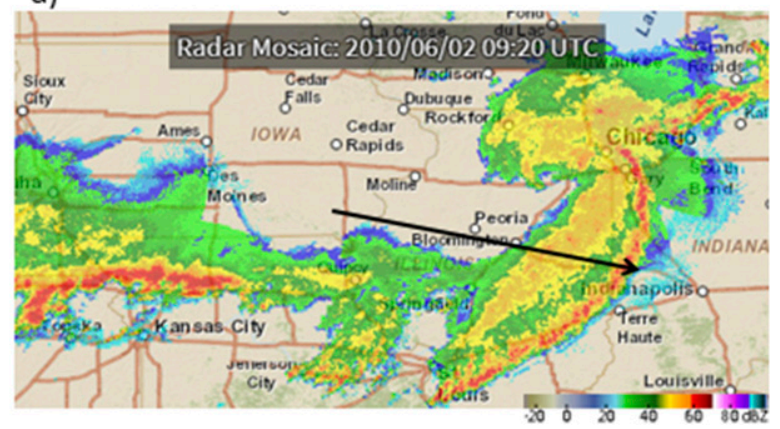

FIG. 2. Radar reflectivity of an MCS (a) $1 \mathrm{~h}$ before reaching maturity, (b) at the time it reaches maturity, (c) halfway through the mature stage, and (d) at the time dissipation begins. Only the forward-propagating portion on the eastern edge of the MCS is considered, which is indicated with the oval in (a). The MV is indicated by the black arrow in (b), (c), and (d). (Images were produced with the NCEI's radar map.)

path followed by the 131 MCSs under consideration as determined by the MV. The identification of storm features through radar reflectivity imagery was done subjectively, as in many other studies (e.g., CBWC; Coniglio et al. 2010; C17).

In addition to the categorization by stage of development, we consider C17's classification of MCSs by degree of organization at maturity, wherein events in categories 1 and 2 are merged into a group of 69 highly organized systems, while categories 3 and 4 are merged into a group of 62 weakly organized storms. Within this context, "highly organized" means the presence of persistent mesoscale bow echoes, arcing convective lines with contiguous high $(>50 \mathrm{dBZ})$ reflectivity, and/or mesoscale convective vortices (see $\mathrm{C} 17$ for more details). This classification, which was performed before the present study's conception, provides an independent means for evaluating the relationship between metrics and MCS dissipation. More specifically, among the metrics that discriminate between the highly and weakly organized MCSs at maturity, losing this discriminatory ability at the dissipation stage is considered a favorable quality in terms of diagnosing system maintenance, as the dissipating stage corresponds to storm disorganization.

\section{b. Index computations using RUC/RAP data}

Environmental metrics were computed using on-time (i.e., nonforecast) hourly analysis data from the RUC and RAP models at $20-\mathrm{km}$ grid spacing provided by NCEI (model domain and topography are shown in Fig. 3). Coniglio et al. (2010) showed that 20-km RUC analyses capture key synoptic-scale features associated with MCSs, and we expect the same to hold for the more recent RAP data. Still, it is important to note that lowtropospheric moisture errors in the RUC and RAP models have been documented by Coniglio (2012) and Peters et al. (2017), respectively, affecting variables of interest, such as precipitable water (PW) and CAPE indices. The latter study showed that such errors in the near environment of an MCS can significantly affect system structure and maintenance, allowing for the possibility of biases in results presented herein, especially if systematic errors arise in association with environmental features related to the organization and dissipation of MCSs. While these limitations warrant caution, we consider that, in the absence of more 


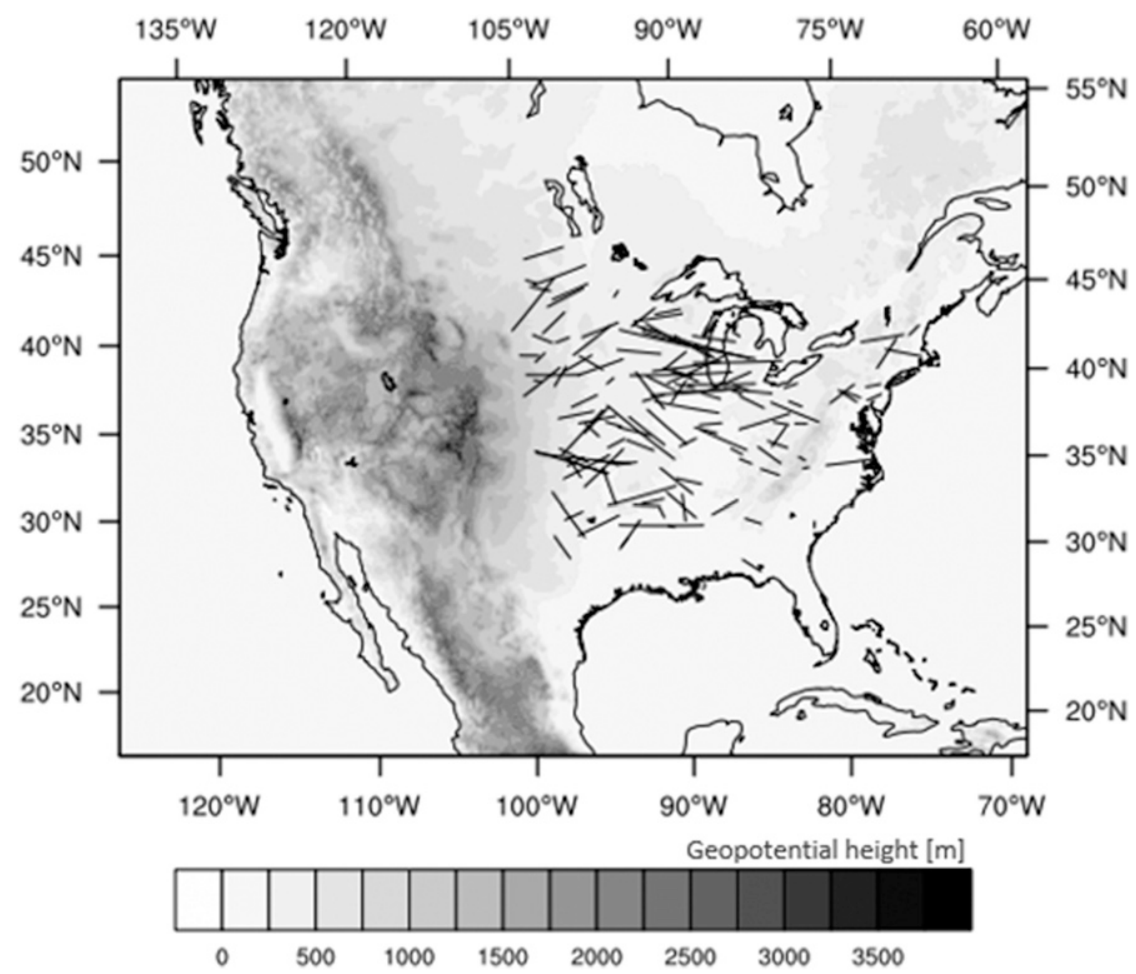

FIG. 3. MCS trajectories during the mature stage (black lines) projected onto the RUC domain. The movement of all MCSs has an eastward component. The RUC/RAP model topography at $20-\mathrm{km}$ grid spacing is contoured for reference.

detailed analyses of model errors, RUC/RAP analyses are suitable for the objectives and methods of this study, as they provide state-of-the-art data for characterizing near-storm environments with reasonable accuracy on average (e.g., Thompson et al. 2003).

MCS environmental variables are computed by averaging RUC/RAP data over a disk with $60-\mathrm{km}$ radius and centered at a point on the path of the MCS located a distance $\max (40 \mathrm{~km}, \mathrm{SS} / 2700 \mathrm{~s})$ ahead of the system's leading edge (Fig. 4). Averaging is performed to reduce the dependence of results on the specific location of the MCS's leading edge, as significant variations can occur on the mesoscale, while observed radar reflectivities and those represented by RUC/RAP models do not coincide exactly. The average within the disk is weighted radially from the center by $\gamma \cos [(\pi / 2)$ (distance from edge $/ 30000 \mathrm{~m})]$, where $\gamma$ ensures that the weights add to 1 . Also, grid points with simulated reflectivity $>30 \mathrm{~dB} Z$ are excluded from the

\footnotetext{
${ }^{2}$ This procedure does not guarantee that the environment is free from convective contamination, as grid points that were recently convecting or with the presence of cold pools from nearby storms could be included. We expect such impacts to be limited because of the weighted averaging of variables.
}

average, to minimize environmental contamination from deep convecting grid points. ${ }^{2}$ Results shown in future sections were not affected significantly by varying the environment's radius to 40 and $80 \mathrm{~km}$, the same

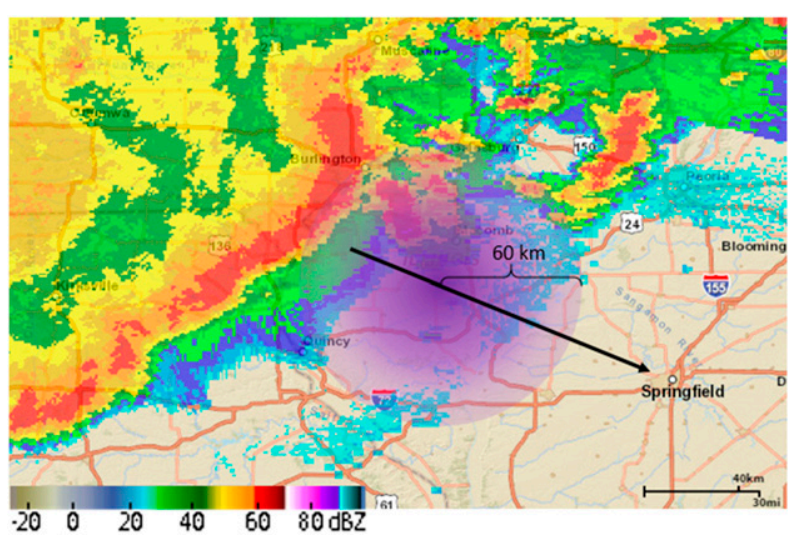

FIG. 4. Illustration of the environment (purple area) over which metrics are averaged, defined as a circular region of $60-\mathrm{km}$ radius, centered at least $40 \mathrm{~km}$ ahead of the MCS in the direction determined by MV (black arrow), and excluding RUC/RAP reflectivities greater than $30 \mathrm{~dB} Z$. Greater transparency toward the edge of the purple area represents lower weights for averaging metrics. 
TABLE 1. Metrics under consideration. Subscripts specify the layer over which metrics are computed $(\mathrm{km})$. The overbar denotes an average over the specified layer.

\begin{tabular}{|c|c|}
\hline $\begin{array}{c}\text { Thermodynamic and } \\
\text { hybrid metrics }\end{array}$ & Kinematic metrics \\
\hline $\begin{array}{l}\mathrm{CAPE}_{\mathrm{ll}} \\
\mathrm{ICAPE} \times \mathrm{IF}_{3} \\
\mathrm{ICAPE} \\
\text { MLCAPE } \\
\text { MUCAPE } \\
\mathrm{PW} \\
\mathrm{PW}_{0-2} \\
\mathrm{PW}_{2-6} \\
\mathrm{LR}_{0-1.5} \\
\mathrm{LR}_{0-3} \\
\mathrm{LR}_{1.5-6} \\
\mathrm{LR}_{3-6} \\
\mathrm{Logit}_{-} \mathrm{CBWC}\end{array}$ & 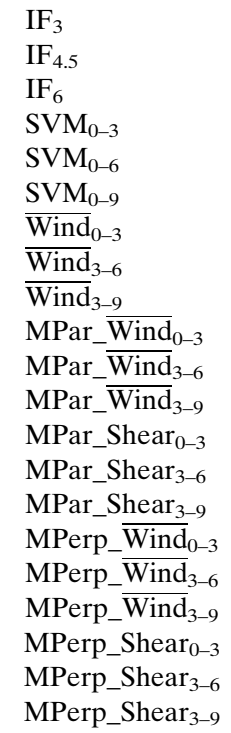 \\
\hline
\end{tabular}

being true for variations in the location of the center of the disk.

For each MCS, two sets of indices are considered: one representative of maturity and the other of the dissipating stage. This specification is required to apply the hypothesis testing techniques described in the next subsection. Metrics at maturity correspond to time averages of the respective variables calculated from RUC/RAP files during the period in which the MCS is categorized as mature. Metrics for the dissipating stage were computed analogously for the first $2 \mathrm{~h}$ after dissipation begins, assuming the SS (MV) does not change in magnitude (direction), which is reasonable given the weighted averaging used to define the environment. The 2 -h period was determined arbitrarily to allow for more than one RUC/RAP file being involved in the computation of the metric at dissipation. The MV determines motion-parallel and motion-perpendicular directions, which are usually very similar to the line-perpendicular and line-parallel directions, respectively, for the MCSs examined in this study (see C17).

A reduced number of indices were selected based on results by CBWC. The metrics under consideration and their respective acronyms are listed in Table 1 . Model data were interpolated from pressure levels into a height grid above ground level (AGL) with a constant spacing of $250 \mathrm{~m}$. The nomenclature is such that the name/ acronym of the metric is specified first, followed by a subscript with the layer determining the variable (in $\mathrm{km}$ ); for example, $\mathrm{SVM}_{0_{-3}}$ is the $0-3-\mathrm{km}$ shear vector magnitude (see Table 1). The integral for calculating CAPE [Eq. (2)] and IF indices [Eq. (4)] is done up to $9 \mathrm{~km}$. Motion-parallel winds are system relative and positive for inflow toward the MCS, while $90^{\circ}$ clockwise rotation of that direction corresponds to positive motionperpendicular winds. CBWC's MCS maintenance probability index is Logit_CBWC, defined by fitting a logistic regression model onto the system stage (mature or dissipating) using four independent variables: deep shear magnitude, midtropospheric lapse rates, mean tropospheric winds above $3 \mathrm{~km}$, and CAPE. The parameters used for Logit_CBWC are as in CBWC, providing an a priori benchmark metric relative to which $\mathrm{CAPE}_{\mathrm{ll}}$ is evaluated. This study does not strictly contemplate RKW indices due to difficulties associated with estimating the cold pool intensity (e.g., Corfidi 2003; Bryan et al. 2005), but lower-tropospheric shear, a primary component of RKW metrics, is included in the metric evaluations.

\section{c. Determining metric performance with nonparametric statistical analyses}

Following CBWC, metrics are evaluated per their ability to discriminate MCS stage and the degree of organization using nonparametric hypothesis testing, which does not require prior knowledge of the probability distribution and is resistant to outliers. Two techniques, the Mann-Whitney $U$ test and the Wilcoxon signed-rank test, are employed to quantify the extent to which a metric's location (a measure of a dataset's magnitude, e.g., the mean in parametric statistical inference) differs between two groups, that is, between mature and dissipating storms, or between highly and weakly organized mature MCSs. These tests are convenient because, for a large enough sample, inferences are based on statistics that are approximately normally distributed under the null hypothesis, with known mean and variance. A brief overview of these statistical inferences is presented below. The reader is referred to Wilks (2006) for a more detailed treatment.

Statistical tests are performed under the assumption that MCSs occur independently from each other, with the null hypothesis being that a metric's location is identical between two groups. Intergroup differences in location are assessed through statistics that depend on metric ranking (i.e., the ordering of observations by metric value; see Table 2). The Mann-Whitney $U$ test, for example, assesses intergroup location differences through the Mann-Whitney $U$ statistic, which depends on the summation of ranks over data 
TABLE 2. Examples used to describe the basic principles behind the Mann-Whitney and Wilcoxon hypothesis testing techniques. See text for more details.

\begin{tabular}{|c|c|c|c|c|c|c|c|}
\hline Event No. & $\begin{array}{l}\mathrm{SVM}_{0-3} \\
\text { mature }\end{array}$ & $\begin{array}{c}\mathrm{SVM}_{0-3} \\
\text { dissipating }\end{array}$ & $\begin{array}{l}\text { Rank } \\
\text { mature }\end{array}$ & Organization & $\begin{array}{c}\left|\Delta \mathrm{SVM}_{0-3}\right|: \\
\mid \text { mature }- \text { dissipating } \mid\end{array}$ & $\begin{array}{c}\text { Rank } \\
\left|\Delta \mathrm{SVM}_{0-3}\right|\end{array}$ & $\begin{array}{c}\text { Sign of } \\
\Delta \mathrm{SVM}_{0-3} \\
\end{array}$ \\
\hline 1 & 13.8 & 16.2 & 3 & 1 & 2.4 & 2 & - \\
\hline 2 & 20.8 & 18.7 & 6 & 1 & 2.1 & 1 & + \\
\hline 3 & 18.2 & 12.6 & 5 & 2 & 5.6 & 4 & + \\
\hline 4 & 11.7 & 4.6 & 1 & 2 & 7.1 & 5 & + \\
\hline 5 & 14.6 & 7.3 & 4 & 1 & 7.3 & 6 & + \\
\hline 6 & 13.4 & 9.9 & 2 & 2 & 3.5 & 3 & + \\
\hline
\end{tabular}

belonging to one of the groups. The logic is that the group with greater location is likely to produce larger (smaller) sums of metric ranks, if the rank ordering is ascending (descending). For illustrative purposes, Table 2 displays $\mathrm{SVM}_{0-3}$ observations corresponding to six MCSs, together with metric ranks at maturity (in ascending order) and labeling by degree of organization in columns 4 and 5, respectively. The sums of $\mathrm{SVM}_{0-3}$ ranks for highly and weakly organized MCSs are 13 and 8 , respectively, indicating that the location of the former group could be greater than the latter. The Mann-Whitney $U$ test is used to determine the significance of such results for differences in metric locations, under the null hypothesis that labeling by group membership is arbitrary in relation to metric rank sums.

The Wilcoxon signed-rank test is applied to cases having significant intergroup metric correlations per event, for example, the correlation of a metric at maturity and dissipation, where samples from the two groups are paired by MCS occurrence. To account for intergroup correlations, it is the magnitude of metric differences from maturity to dissipation that are ranked (see column 6 in Table 2), and inferences are performed on the Wilcoxon $T$ statistic, which depends on the summation of those ranks over events in which the metric at maturity is greater than at dissipation. ${ }^{3}$ For example, columns 6, 7, and 8 in Table 2 display the absolute values of interstage metric differences, their ranks, and the labeling by the sign of the difference of $\mathrm{SVM}_{0-3}$ at maturity and dissipation, respectively. The sum of ranks labeled with a plus sign $(+; 19)$ is considerably larger than the sum of ranks labeled a minus sign $(-; 2)$, so the sample appears to indicate that the location of the mature group is greater than the

\footnotetext{
${ }^{3}$ Note that, by focusing on metric value differences, the interstage correlation is somewhat controlled for, given that a large metric value at dissipation in association with a large value at maturity (due to the correlation) does not necessarily imply a large magnitude of their difference.
}

location of the dissipating group, the significance of which is assessed through the Wilcoxon signedrank test.

Results from statistical inferences are presented through $Z$ scores, which quantify the difference between the sampled statistic and its mean value in the number of standard deviations. The mean and standard deviation correspond to the statistic's distribution under the null hypothesis. Given that a greater $Z$ score implies greater confidence in null hypothesis rejection, $Z$ scores are interpreted as a measure of intergroup discriminatory ability. Only $Z$-score magnitudes $>\sim 2$ (0.05 statistical significance) are reported, with the tests being one sided as deduced from previous investigations and arguments in section 2, except for motion-parallel winds, for which it is not clear whether stronger or weaker values favor MCS maintenance and organization.

In section 4, the Wilcoxon signed-rank test is used to evaluate metrics per their ability to identify the transition from maturity to dissipation, thus contemplating interstage metric correlations. ${ }^{4}$ In section 5, the MannWhitney $U$ test is applied in two different problems, wherein the independence of events is guaranteed by considering one metric per MCS. First, events are partitioned into two groups in section 5 by randomly choosing a stage for each MCS, allowing metric evaluations in terms of their ability to differentiate between mature and dissipating storms. Second, in section 6 the Mann-Whitney $U$ test is applied within the context of C17's categorization by degree of organization, both at maturity and dissipation. This analysis is intended to identify the primary drivers of the disorganization that characterizes the dissipating stage. Section 7 illustrates how to interpret the results from nonparametric analyses for practical applications.

\footnotetext{
${ }^{4}$ The case-by-case interstage Pearson correlation coefficient of metrics listed in Table 1 lies between $0.58\left(\mathrm{CAPE}_{11}\right)$ and 0.9 (MPar_Wind $\left.{ }_{0-3}\right)$, values that have near-zero probability of arising by chance.
} 
a)

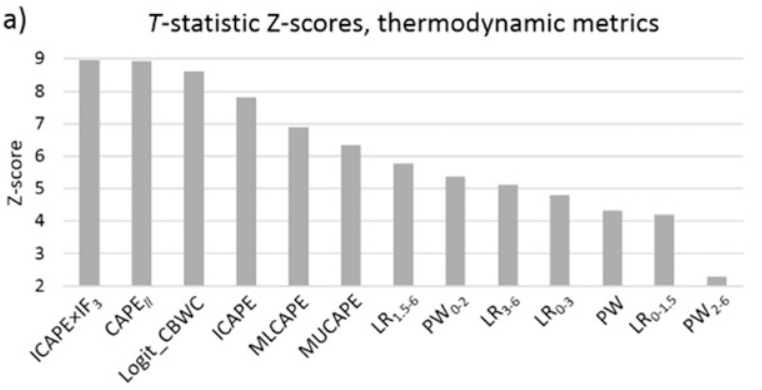

b)

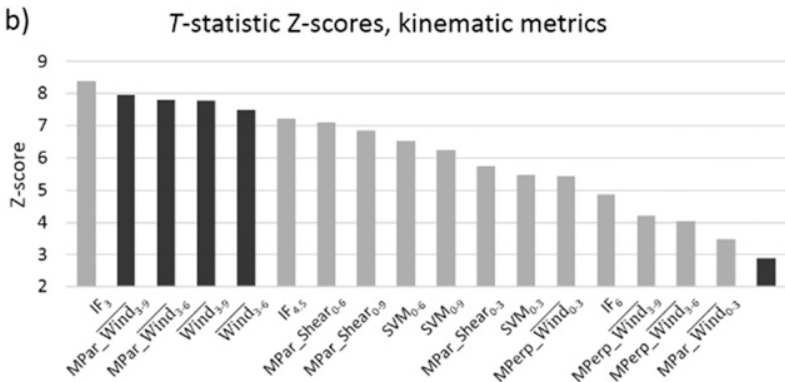

FIG. 5. The $Z$ scores of Wilcoxon $T$ statistics for (a) thermodynamic and (b) kinematic metrics. Metrics that increase in value from maturity to dissipation are indicated by darker bars.

\section{Evaluation of metric change from maturity to dissipation}

This section analyzes each metric's ability to determine when MCSs dissipate, using the Wilcoxon signed-rank test to evaluate interstage changes in metric values. The interpretation follows naturally from the definition of the Wilcoxon $T$ statistic, which depends on the difference between a metric value representative of the mature stage and its corresponding value at dissipation for each event (see section 3c). This implies that the test pertains to interstage metric variations, a matter that is discussed further in section 7.

Before embarking on a more detailed analysis, it is worth highlighting that most indices attain relatively large $Z$ scores, as shown in Fig. 5. This is partly due to metrics being selected based on by their relevance to MCS maintenance, as determined by previous studies (e.g., CBWC). The importance of the selection criteria is corroborated by computing the $Z$ score of the $500-\mathrm{hPa}$ geopotential height, which at 0.1 is very low in relation to the $Z$ scores of metrics considered in this study. However, that so many kinematic and thermodynamic indices attain $Z$ scores greater than 5 indicates that MCSs dissipate as they move into regions that differ systematically from the environments where they originate and mature. This does not imply that all metrics under consideration are relevant to MCS maintenance, but it does suggest that they all tend to vary in concert with environmental features that lead to storm dissipation. The intervariable correlation implied by this observation represents one of the most challenging aspects for identifying the drivers of MCS dissipation.

\section{a. Thermodynamic metrics}

The $Z$ scores attained by thermodynamic metrics are shown in Fig. 5a, including $\mathrm{CAPE}_{11}, \mathrm{ICAPE} \times \mathrm{IF}_{3}$, and Logit_CBWC, which are hybrid in the sense that they also depend on kinematics. The best performers of all metrics listed in Table 1 are CAPE 11 and $\mathrm{ICAPE} \times \mathrm{IF}_{3}$.
These indices have very similar $Z$ scores as a result of their large Pearson correlation coefficient (0.92), validating the approximation in Eq. (3). The second-best discriminator is Logit_CBWC, which indicates consistency with CBWC's results, wherein Logit_CBWC was defined by fitting a logistic regression to observations of the best-performing indices. That $\mathrm{CAPE}_{11}$ outperforms Logit_CBWC could result from the former capturing relevant environmental impacts on MCS maintenance that depend nonlinearly on traditional indices, as exemplified by the product in ICAPE $\times \mathrm{IF}_{3}$ (see section 2); however, this feature is unlikely to be identifiable statistically with the relatively small number of events considered herein. In addition, the $Z$ score of ICAPE is larger than those of most-unstable CAPE (MUCAPE) and mixed-layer CAPE (MLCAPE), suggesting the importance of considering latent heating by parcels over the depth of the positive CAPE layer. In general, these results are consistent with the layer-lifting interpretation of convective instability in forward-propagating MCSs.

Among lapse rate (LR) and PW metrics, which appear to be less skillful than CAPE indices, the LR between $1.5 \mathrm{~km}$ (roughly cloud base) and the midlevels stands out, in agreement with Gale et al. (2002) and CBWC, while $\mathrm{PW}_{0-2}$ attains the largest $Z$ score among the moisture variables, a feature that is influenced by the Great Plains low-level jet (LLJ; Bonner 1968). The physical basis for the skill of $\mathrm{LR}_{1.5-6}$ could be related to the fact that, for a given water vapor mixing ratio profile, steep low- to midtropospheric LRs support large ICAPE (see AK). ${ }^{5}$ This might seem at odds with the relatively low correlation between ICAPE and $\mathrm{LR}_{1.5-6}$ $(\approx 0.2)$; however, elevated mixed layers in the Great

\footnotetext{
${ }^{5}$ The skill of $\mathrm{LR}_{1.5-6}$ could also be related to potential instability (the magnitude of the change of equivalent potential temperature with height); however, in numerical experiments considered by AK, ICAPE has a stronger impact on MCS organization and intensity than potential instability.
} 
Plains, where many MCS occur (Fig. 3), are associated with dry air from the Mexican Plateau and the Rocky Mountains (Carlson et al. 1983), which tends to reduce ICAPE. Indeed, $\mathrm{LR}_{1.5-6}$ and $\mathrm{PW}_{2-6}$ are significantly anticorrelated $(\approx-0.5)$, perhaps explaining the relatively low $Z$ score of the latter. However, moist conditions aloft do appear to favor MCS maintenance, as suggested by the diagnostic improvement of ICAPE over MUCAPE and MLCAPE, as well as $\mathrm{PW}_{2-6}$ reaching the statistical significance threshold.

\section{b. Kinematic metrics}

Figure 5 b shows $Z$ scores of kinematic indices, excluding motion-perpendicular (MPerp; roughly line parallel) shear (MPerp_Shear) and low-tropospheric mean wind speed (Wind), which do not reach statistical significance. The best discriminator in Fig. $5 \mathrm{~b}$ is $\mathrm{IF}_{3}$, followed by motion-parallel (MPar) mean wind velocities aloft: MPar_ $\overline{W i n d}_{3-9}$ and MPar_Wind ${ }_{3-6}$, and $\overline{\mathrm{Wind}}_{3-9}$ and $\overline{\mathrm{Wind}}_{3-6}$. These indices are strongly interrelated, as larger MPar_Wind values aloft tend to be associated with greater (lower) Wind (IF). CBWC also found mean wind speeds aloft to be skillful predictors of MCS dissipation, and it is likely that IF would have had a relatively good performance if incorporated in that study. Among motion-perpendicular mean wind velocities (MPerp_Wind), MPerp_ $\overline{W i n d}_{0-3}$ has the largest $Z$ score, presumably because of its relationship with moisture transport by the LLJ (e.g., Coniglio et al. 2010).

Considering shear metrics, the best performers are SVM and motion-parallel (roughly line perpendicular) shear (MPar_Shear) computed over deep surface-based layers. Low-tropospheric shear metrics attained lower $Z$ scores, echoing the results of CBWC. Note that the $Z$ score of $\mathrm{IF}_{3}$ is considerably larger than that of $\mathrm{SVM}_{0-3}$ and MPar_Shear ${ }_{0-3}$, supporting the importance of the fraction of inflowing convectively unstable air in the layer-lifting concepts of AK and A17. The decrease in diagnostic skill of the IF indices with increasing depth of the inflow layer [Eq. (4)] is also consistent with the layerlifting framework, as most of the unstable air resides in the lowest $3 \mathrm{~km}$ AGL.

\section{c. Summary of results from the Wilcoxon signed-rank test}

Results from the Wilcoxon signed-rank test indicate that both kinematic and thermodynamic environmental factors vary systematically as severe MCSs dissipate. Still, there are significant differences in metric performance as measured by $Z$ scores, with layer-lifting metrics standing out as effective discriminators of MCS dissipation. The best performers are, in descending order per their $Z$ scores, $\mathrm{CAPE}_{\mathrm{ll}}$, Logit_CBWC, $\mathrm{IF}_{3}$, mean midtropospheric wind speed (MPar_ $\overline{\text { Wind }}_{3-9}$, MPar_ $\overline{\text { Wind }}_{3-6}, \overline{\text { Wind }}_{3-9}$, and $\overline{\text { Wind }}_{3-6}$ ), ICAPE, and deep shear magnitude (MPar_Shear $0-6$, MPar_Shear $_{0-9}$, $\mathrm{SVM}_{0-6}$, and $\mathrm{SVM}_{0-9}$ ). Low-tropospheric shear metrics were less effective at diagnosing MCS stage transitions than $\mathrm{IF}_{3}$, indicating that layer-lifting effects could be more important for driving MCS dissipation than RKW's theory of vorticity balance. However, the lack of accurate cold pool intensity measurements hinders a more rigorous evaluation of RKW theory.

\section{Discrimination of mature and dissipating MCSs}

In this section, the Mann-Whitney $U$ test is used to determine the ability of metrics to differentiate between mature and dissipating MCSs, which requires independence of the data. Although MCSs are assumed to occur independently from each other, as they manifested on separate days, there is a significant correlation between metric values at maturity and dissipation (see section 4). Thus, statistical significance is tested by randomly choosing a stage for each of the 131 MCSs, either mature or dissipating. Only the metric corresponding to the randomly chosen stage is considered for each MCS; that is, there is only one metric per event, guaranteeing data independence. The metric values are then ranked from lowest to highest and the $Z$ score of the differences between the randomly pooled values for the mature and dissipating MCSs is computed [see Wilks (2006) for a thorough description of the MannWhitney $U$-test procedure]. This procedure is repeated 250 times, and a mean statistical significance of at least 0.05 is required for metrics to be considered below. ${ }^{6}$ Results are presented through mean $Z$ scores, which are simply referred to as $Z$ scores. It is worth mentioning that inferences considered herein pertain to actual metric locations, in contrast with the previous section's analyses of interstage metric differences (see also section 7).

Figure 6 displays the $Z$ scores of metrics that reach the statistical significance threshold. CAPE indices stand out as the best discriminators, with $\mathrm{CAPE}_{\mathrm{ll}}$ and ICAPE $\times \mathrm{IF}_{3}$ having the best performance, followed by ICAPE. Also, $\mathrm{IF}_{3}$ is the most skillful among kinematic indices. These results agree with previous analyses based on the Wilcoxon $T$ statistic, again lending weight to the layer-lifting framework.

\footnotetext{
${ }^{6}$ The mean statistical significance is computed by averaging the cumulative probability distribution of the $U$ statistic under the null hypothesis for each random stage selection. It should not be confused with the statistical significance of the average $U$ statistic.
} 


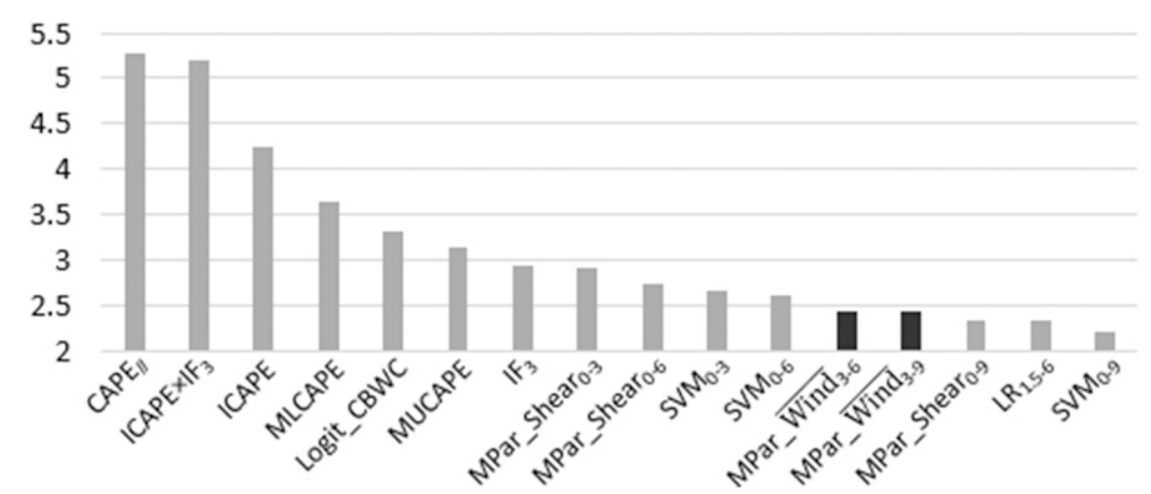

FIG. 6. As Fig. 5, but for MCS stage discrimination per the Mann-Whitney $U$ test.

An interesting aspect of Fig. 6 is that MPar_Shear ${ }_{0-3}$ and $\mathrm{SVM}_{0-3}$ are better at differentiating between mature and dissipating MCSs than their deep shear analogs, contrary to findings presented in the previous section. Thus, while interstage changes in deep shear occur consistently and systematically, indicating system movement toward less baroclinic regions, its actual strength is not as good a predictor of MCS stage as lowtropospheric shear. It is important to note that lowtropospheric shear could partially derive its skill from its indirect relation to latent heating, given its close link to IF for a given wind profile aloft (see A17). ${ }^{7}$ The plausibility of this interpretation is supported by ICAPE's ability to differentiate between stages, which indicates the relevance of convective instability, as well the good performance of MPar_Wind aloft and $\mathrm{IF}_{3}$, suggesting the importance of inflowing low- $\theta_{e}$ air at midlevels. However, statistical analyses considered herein are not sufficient to determine the extent to which the performance of low-tropospheric shear results from indirect impacts on latent heating or from vorticity balance effects on the forced updraft along the cold pool.

\section{Discrimination of MCS organization at maturity}

This section evaluates layer-lifting indices as discriminators of MCS stage per interstage differences in their ability to differentiate C17's categorization of highly and weakly organized mature storms. The logic follows two principles. First, based on results by A17, a relationship is expected between layer-lifting metrics and the degree of MCS organization. Second, among metrics that discriminate between organization categories (which we expect to include layer-lifting indices),

\footnotetext{
${ }^{7}$ The Pearson correlation coefficient between MPar_Shear ${ }_{0-3}$ and $\mathrm{IF}_{3}$ at maturity is $\approx 0.4$.
}

it is assumed that the most likely drivers of MCS dissipation are those that lose their diagnostic skill at the dissipating stage. This assumption is based on the correspondence between dissipation and system disorganization, wherein it is envisaged that all dissipating MCSs should become indistinguishable, in terms of their degree of organization, to the metric that drives stage transition. In other words, all dissipating MCSs are very weakly organized, regardless of their degree of organization at maturity, so it is expected that environmental traits that cease to support system organization, leading to stage transition, should lose their ability to differentiate between categories at the dissipating stage.

The $Z$ scores of metrics that discriminate MCS organization at maturity with 0.05 statistical significance are shown in Fig. 7a, including ICAPE, which barely missed the significance mark. It is evident that layer-lifting indices are not particularly skillful for differentiating between C17's organization categories, even though the $\mathrm{CAPE}_{11}$ and IF metrics do reach the statistical significance threshold. On the other hand, that LRs aloft attain larger $Z$ scores than CAPE $_{11}$ and ICAPE could again indicate the importance of potential instability. The best discriminator is Logit_CBWC, followed by MPar Shear ${ }_{0-9}$, lending weight to the importance of deep shear for MCS organization (Parker and Johnson 2004; Coniglio et al. 2006). The large skill of MPar_Wind ${ }_{0-3}$ is partly a result of more organized storms moving faster, thus developing greater low-tropospheric inflow.

A noteworthy feature in Fig. $7 \mathrm{a}$ is the consistent reduction of all metrics' $Z$ scores from maturity to dissipation, also displayed through $Z$-score differences in Fig. 7b. This trait, which is not shared by some of the less skillful metrics (not shown), is consistent with the equivalency between dissipation and disorganization. Only the metrics $\mathrm{CAPE}_{11}$ and ICAPE have large enough $Z$-score reductions to lose a significant relationship with the degree of MCS organization at dissipation, 
a) MCS organization U-statistic Z-scores

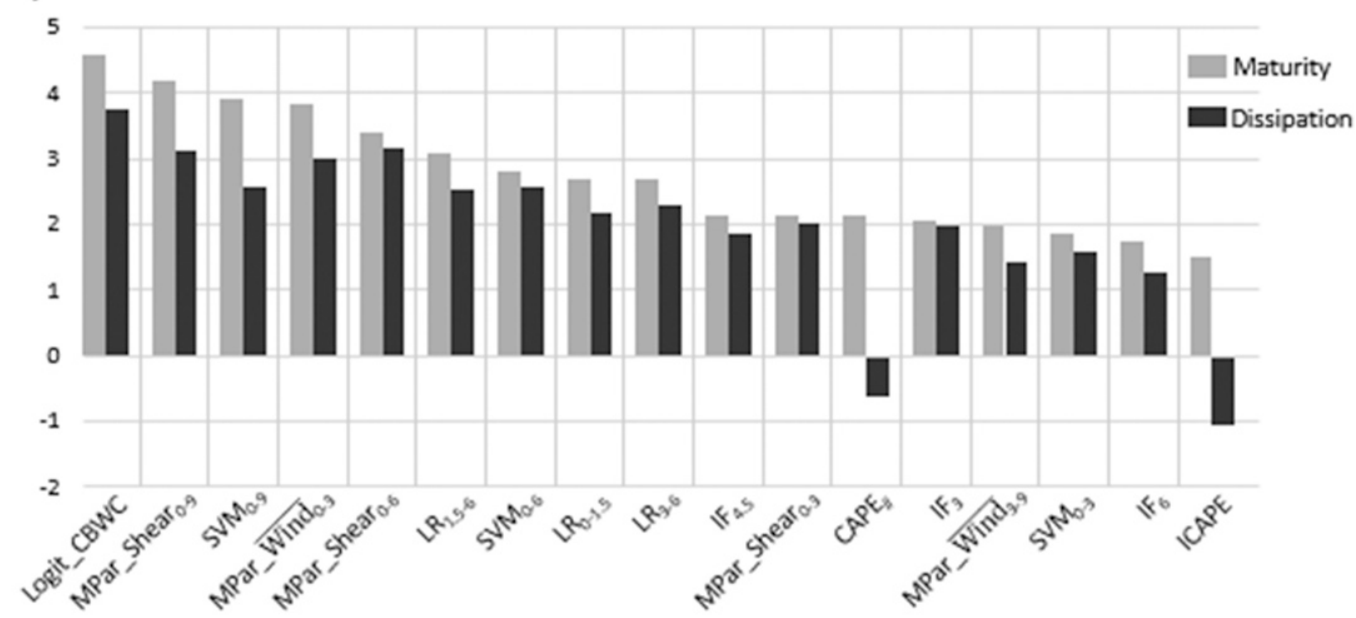

b)

Inter-stage Z-score differences

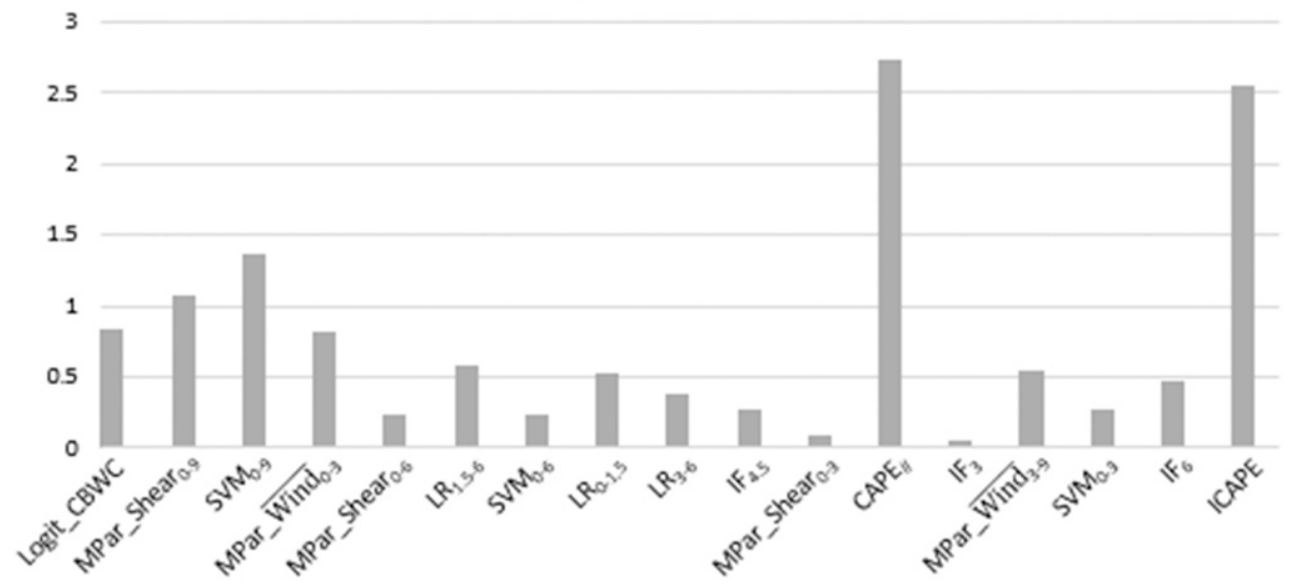

FIG. 7. (a) As in Fig. 6, but for MCS organization discrimination at maturity and dissipation. (b) The interstage $Z$-score differences.

suggesting, per arguments presented above, that system disorganization is driven primarily by diminishing convective instability. Also note that, excluding $\mathrm{CAPE}_{11}$ and ICAPE, deep shear and MPar_Wind ${ }_{0-3}$ attain the largest interstage $Z$-score differences, the former confirming the impacts of deep shear on storm organization/ disorganization, while the latter could reflect the dependence of MCS maintenance on the amount of inflowing convectively unstable air.

\section{Practical interpretation of $Z$ scores resulting from nonparametric hypothesis testing}

Results presented up to this point are based on two different statistical analyses, which produce somewhat contrasting interpretations of the ability of metrics to discriminate mature and dissipating MCSs. For example, results in section 5 suggest that low-tropospheric shear is better at discriminating MCSs by their stage than deep shear indices, while analyses in section 4 indicate the opposite. To interpret these results, it is necessary to consider the functionality of both statistics on which inferences are performed: the Wilcoxon $T$ statistic, which is used in section 4, depends on interstage metric changes, while the Mann-Whitney $U$ statistic, which is used in sections 5 and 6 , is a function of metric ranks (see section $3 c$ ). Thus, the skill of each metric in section 4 is assessed through the change in metric value from maturity to dissipation, while in section 5 (section 6) the skill of each metric pertains to MCS discrimination by stage (degree of organization) through direct use of metric values. The difference is key from a practical perspective. Described next are two examples for how one might apply the results from the statistical analysis, one for diagnosing the MCS 
a) Distribution of standardized best performing metrics

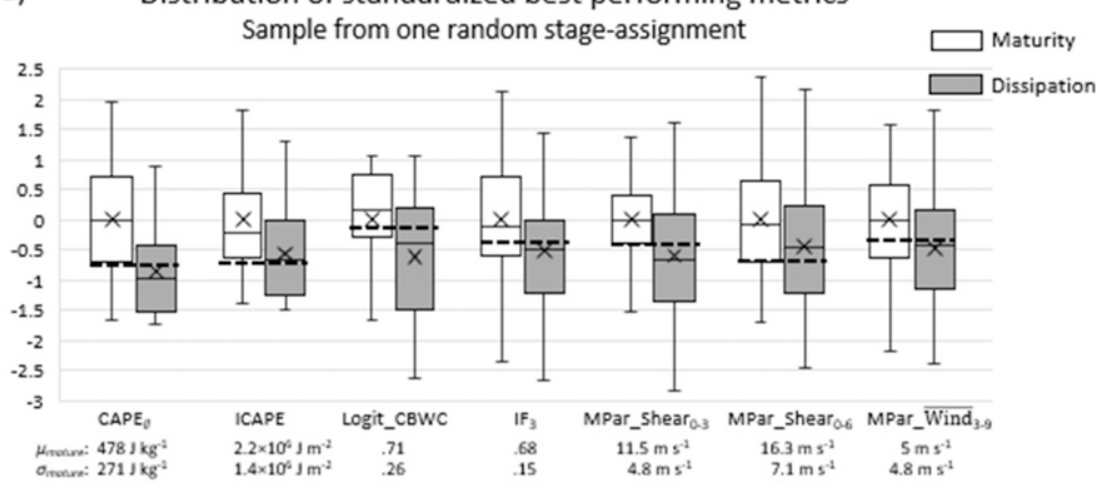

b)

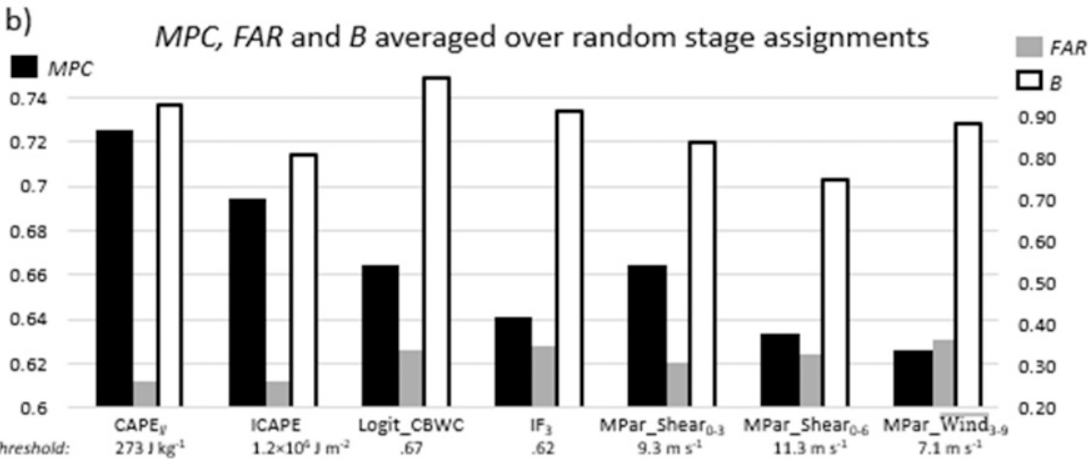

FIG. 8. (a) Box-and-whisker plot of distributions in one of the random stage selections described in section 5, showing best-performing metrics per the Mann-Whitney $U$ test ordered by their $Z$ scores, decreasing from left to right. Indices are standardized by subtracting the mature stage's mean $\mu_{\text {mature }}$ and dividing the result by the mature stage's standard deviation $\sigma_{\text {mature }}$, with both parameters specified at the bottom for reference. The box contains the two central quartiles, the solid horizontal line corresponds to the median, the cross indicates the mean, and the dashed horizontal line indicates the discriminating threshold. (b) The mean MPC over the random value is indicated by the black bars. For reference, gray and white bars indicate the FAR and $B$, with values indicated by the axis on the right. The mean discriminating threshold is indicated at the bottom, for reference.

stage with metric values, and the other pertaining to MCS stage-transition forecasts with interstage metric changes. These examples are meant to illustrate the logic for interpreting results from previous statistical analyses and to provide additional information that might be relevant to forecasters [e.g., in relation to false alarm rates (FAR)]; formal evaluations using independent datasets are left for future work.

First, consider the problem of forecasting MCS stage using the value of a given metric, where maturity or dissipation is determined depending on whether the environmental metric is greater or less than a prespecified threshold. Appropriate metric value thresholds to use in this application are determined by identifying the maximum proportion correct (MPC; the proportion correct is the number of correct forecasts divided by the number of events) achievable with a given threshold. For each standardized metric distribution, the MPC is determined by a threshold (thick dashed line in Fig. 8a) that maximizes the sum of mature events lying above and dissipating events lying below [i.e., correct classifications (or sum of hits and correct negatives)]. For example, considering $\mathrm{CAPE}_{11}$ in Fig. 8a, in which a standardized value of -0.75 (equivalent to $270 \mathrm{~J} \mathrm{~kg}^{-1}$ ) maximizes the number of correct classifications, 50 mature MCSs have $\mathrm{CAPE}_{11}$ values above this threshold, while 45 dissipating MCSs have $\mathrm{CAPE}_{11}$ values below it, implying $\mathrm{MPC}=95 / 131 \approx 73 \%$. For this application, the stage diagnosis depends exclusively on a metric's value, wherein greater skill should be achieved by metrics having a larger difference in location between maturity and dissipation. Thus, analyses in section 5 are expected to be relevant to this application, which is why, for consistency on independence of events, the MPC is computed for each of the 250 random stage selections described in section 5, and results are 


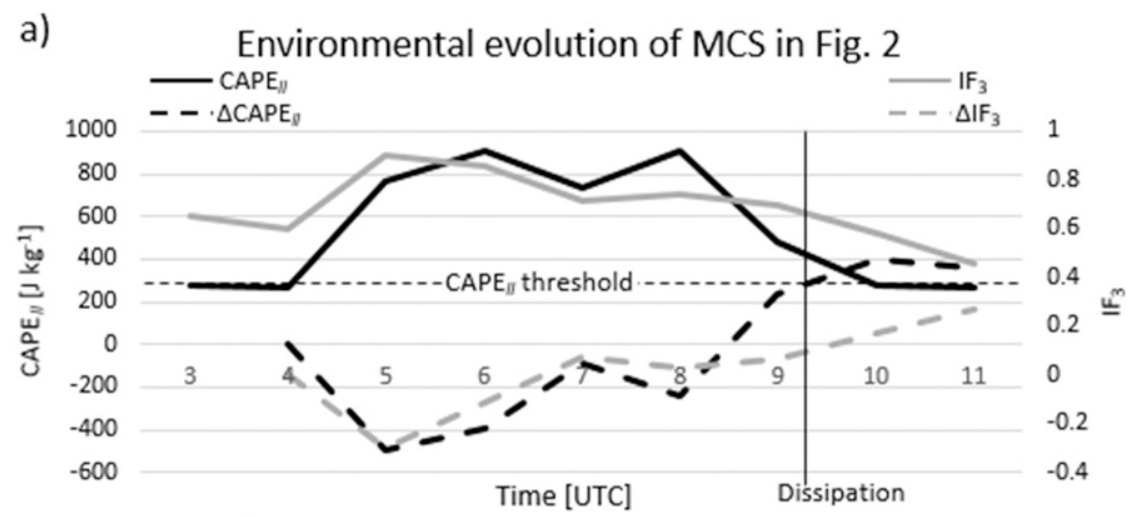

b)

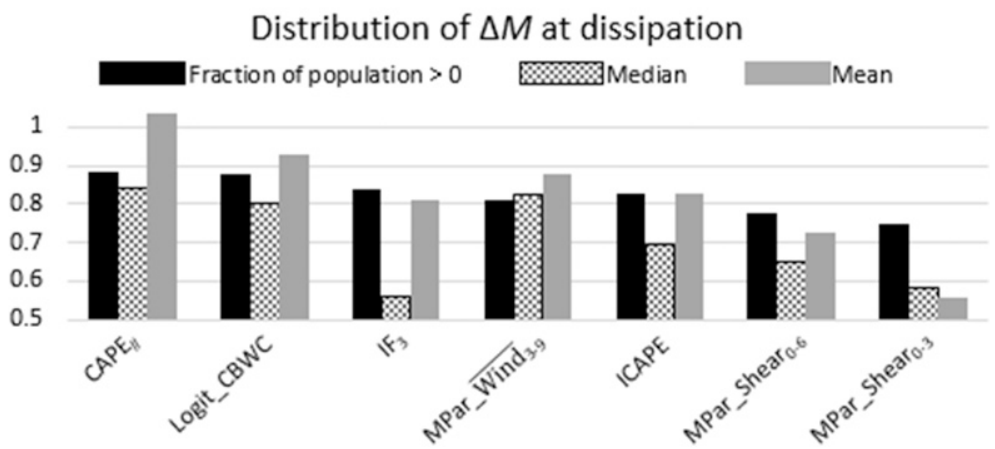

FIG. 9. (a) The evolutions of $\mathrm{CAPE}_{\mathrm{ll}}$ (thick black line), $\mathrm{IF}_{3}, \Delta \mathrm{CAPE}_{\mathrm{ll}}$, and $\Delta \mathrm{IF}_{3}$ for the MCS depicted in Fig. 2. When maturity is reached, $\Delta M$ is assumed to equal zero (see text for details). The threshold for $\mathrm{CAPE}_{\mathrm{ll}}$ in Fig. $8 \mathrm{~b}$ is indicated by the thin dashed horizontal line, and the time at which dissipation initiates is indicated by the thin solid vertical line. (b) The mean, median, and fraction of population $>0$ of $\Delta M$ at dissipation for metrics displayed in Fig. 8, divided by the standard deviation of the population. Metrics are ordered by their Wilcoxon $Z$ scores, decreasing from left to right.

presented as averages over each realization (distributions in Fig. 8a correspond to one trial of randomly selected stages).

Results in Fig. 8b corroborate that the ordering of metrics by MPC is in broad agreement with the ordering by $Z$ scores in section 5 , with the exception being that MPar_Shear ${ }_{0-3}$ performs better relative to other metrics per the former evaluation. This discrepancy illustrates that there is a difference between working directly with metric values and their ranks (see section $3 c$; working with metric values allows influence from outliers). Figure $8 \mathrm{~b}$ also displays the FAR and the bias $B$ implied by the MPC threshold, where, by labeling dissipation (maturity) as a "yes" ("no") forecast or event, FAR is the fraction of false alarms among yes forecasts, while $B$ is the ratio of yes forecasts to yes events. The metric $\mathrm{CAPE}_{11}$ stands out as having the lowest FAR (26\%), while also being the second least biased, after Logit_CBWC, with $B \approx 93 \%$. Note that $\mathrm{IF}_{3}$ has the second largest FAR, after MPar_ $\overline{\text { Wind }}_{3-9}$, which is related to its poor performance (compared to other metrics) per the MPC in relation to $Z$-score evaluations.

In practice, metric evolution could be even more relevant to assessing MCS maintenance than the "snapshot" values considered in the example above. To illustrate this, consider the evolution of $\mathrm{CAPE}_{11}$ in the environment of the MCS depicted in Fig. 2 and shown in Fig. $9 \mathrm{a}\left(\mathrm{IF}_{3}\right.$ is also displayed for reference). The value of $\mathrm{CAPE}_{11}$ is relatively small between 0300 and 0400 UTC (see Figs. 2a and 2b), around the time when the system reaches maturity, with values resembling those attained at dissipation (0920 UTC; see Fig. 2d). These values, around $265 \mathrm{~J} \mathrm{~kg}^{-1}$, might suggest that the system will be short lived, for example, considering the threshold discussed in the previous application (indicated by thin dashed line in Fig. 9a). However, given that $\mathrm{CAPE}_{11}$ remains nearly constant between 0300 and 0400 UTC, one could argue that conditions remain favorable for the maintenance of that MCS; that is, dissipation is expected only after environmental conditions deteriorate. Afterward, $\mathrm{CAPE}_{\mathrm{ll}}$ increases considerably, reaching $900 \mathrm{~J} \mathrm{~kg}^{-1}$ 
at 0600 UTC, a period during which the system intensified and became more organized (see Fig. 2c). The MCS maintains its highly organized structure as $\mathrm{CAPE}_{\mathrm{ll}}$ remains relatively large (not shown). The system dissipates shortly after CAPE 11 decreases significantly.

Motivated by the example above, one might want to analyze the problem of MCS dissipation through metric changes. Such changes can be measured with $\Delta M=\bar{M}-M_{\text {now }}$, where $M$ is a generic reference to metrics and the overbar represents an average of observed $M$ values from the onset of maturity and excluding the most recent observation, denoted as $M_{\text {now }}$ ( $M_{\text {now }}$ could be a forecast value). Basically, $\Delta M$ provides information on whether the environment becomes more or less favorable for MCS maintenance than the one where the mature system thrived. For example, Fig. 9a shows that $\triangle \mathrm{CAPE}_{11}$ attains positive values around the time the system dissipates, indicating deteriorating conditions for MCS maintenance. More generally, Fig. 9b shows that the distributions of $\Delta M$ at dissipation (i.e., the metric changes in section 4) of the bestperforming metrics per analyses in section 4 lie mostly above zero, suggesting a strong relation between metric changes and MCS dissipation and explaining the large $Z$ scores in Fig. 5. It is also worth highlighting that metrics with higher Wilcoxon $Z$ scores have $\Delta M$ populations lying farther above zero (Fig. 9b), which indicates some degree of correspondence between a metric's forecasting skill through $\Delta M$ and results in section 4 . In this regard, if a threshold is applied to $\Delta M$ for forecasting MCS dissipation, as in the previous application, populations lying farther from zero are likely to have larger optimal thresholds, potentially reducing their FAR. However, a formal assessment of metric performance through $\Delta M$ requires analyses that are beyond the scope of this study.

\section{Definition and evaluation of an operational CAPE $_{\mid l}$ using Corfidi vectors}

Previous analyses indicate that $\mathrm{CAPE}_{11}$ could be useful in forecasting applications. The difficulty lies in $\mathrm{CAPE}_{11}$ not being a purely environmental index, as its value depends on the MCS's MV, which is partly governed by mesoscale processes associated with the storm's manifestation. To overcome this shortcoming, we diagnose MV using Corfidi vectors in forwardpropagating MCSs (Corfidi 2003), leading to a Corfidi layer-lifting CAPE (CAPE ll_Corfidi $\left._{2}\right)$. Corfidi vectors consider the movement of MCSs as the sum of an advective component, assuming individual cells move with the mean cloud-layer winds (MCLW), and a propagating component, given by the movement of the cold pool's edge, where new cells are continuously triggered. In results presented below, MCLW is computed by averaging wind velocities between 1.5 and $8.5 \mathrm{~km}$ AGL, while propagation is estimated as the difference between MCLW, which captures the effects of downward momentum transport by the rear-inflow jet (e.g., see Mahoney et al. 2009), and the wind velocity at $850 \mathrm{hPa}$, representing forcing by the LLJ. For more details, see Corfidi (2003).

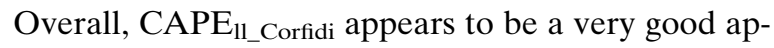
proximation to $\mathrm{CAPE}_{\mathrm{ll}}$, as revealed by their high Pearson correlation $(\approx 0.85$ at maturity and $\approx 0.95$ at dissipation) and the similarity of their distributions, shown in Fig. 10. Thus, both metrics have similar $\Delta M_{\text {final }}$ distributions, also displayed in Fig. 10, showing that dissipation is likely to occur as CAPE $\mathrm{Cl}_{11 \text { Corfidi }}$ decreases in one standard deviation (roughly $230 \mathrm{~J} \mathrm{~kg}^{-1}$ ). It is worth noting that this threshold is too large (small) in

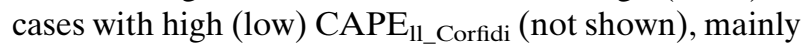
because the $\Delta M_{\text {final }}$ of $\mathrm{CAPE}_{\mathrm{ll}}$ is significantly correlated with $M_{\text {mature }}(\approx 0.7$ Pearson coefficient). Therefore, it might be useful to consider $\Delta M_{\text {final }} / M_{\text {mature }}$ instead of $\Delta M_{\text {final }}$ when applying $\mathrm{CAPE}_{\text {ll_Corfidi }}$ to forecast MCS maintenance. Indeed, Fig. 10 shows that $\Delta M_{\text {final }} / M_{\text {mature }}$ spans a more compact range than $\Delta M_{\text {final, while both }}$ have similar means/medians, which is favorable in terms of forecast precision.

In agreement with their large correlation and the similarity of their distributions, CAPE ll_corfidi and $_{2}$ $\mathrm{CAPE}_{11}$ display similar abilities to discriminate MCS stage and stage transition, shown via $Z$ scores in Fig. 11. The main difference between $\mathrm{CAPE}_{11}$ and $\mathrm{CAPE}_{11 \_ \text {Corfidi }}$ is in their ability to differentiate between organization categories at maturity (Fig. 11), the latter attaining a slightly lower $Z$ score than ICAPE. This results from a bias in the direction of Corfidi vectors, which are rotated $10^{\circ}$ counterclockwise from MV, on average. Such bias has a large impact on the skill of CAPE $\mathrm{ll}_{11}$ Corfidi because, although motion-parallel indices are among the best discriminators of MCS organization (see Fig. 7), motionperpendicular metrics are among the worst (not shown), implying high diagnostic sensitivity to the direction of MCS movement. ${ }^{8}$ However, the organization $Z$ score of $\mathrm{CAPE}_{11 \text { Corfidi }}$ changes considerably from maturity to dissipation, consistent with this metric's relation to system disorganization. In general, results presented above support the potential of CAPE $\mathrm{Cl}_{11}$ Corfidi as a useful guide for MCS maintenance forecasting.

\footnotetext{
${ }^{8}$ The direction bias in Corfidi vectors is not consistent enough to improve the discriminatory skill of CAPE $\mathrm{Il}_{\text {l_Corfidi }}$ by simply rotating Corfidi vectors $10^{\circ}$ clockwise.
} 


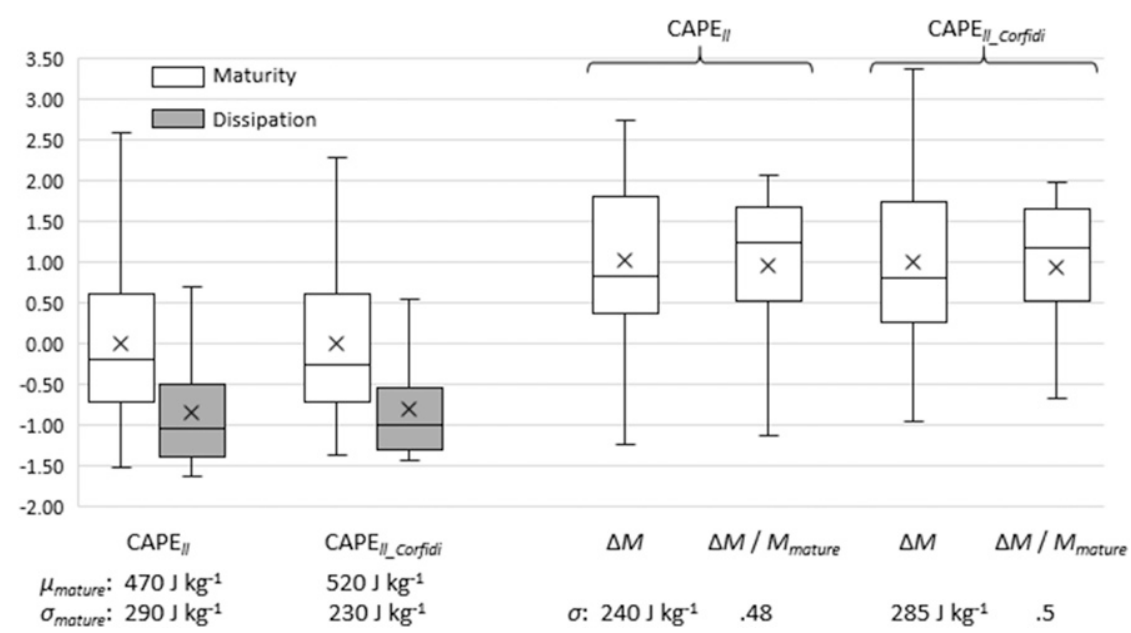

FIG. 10. As in Fig. 8a, but comparing the distributions of (left) $\mathrm{CAPE}_{\mathrm{ll}}$ and $\mathrm{CAPE}_{\mathrm{ll} \_ \text {Corfidi }}$ at maturity and dissipation, as well as (right) their $\Delta M$ and $\Delta M / M_{\text {mature }}$ at dissipation.

\section{Summary and discussion}

This observational study evaluates the diagnostic capability of layer-lifting indices for determining the maintenance of severe-wind-producing MCSs, focusing on forward-propagating systems occurring during the warm months over the continental United States. Using meteorological radar imagery, the time and location at which each event reaches maturity and dissipation is subjectively identified, allowing the determination of an environment representative of each stage, as well as an MCS movement vector. RUC/RAP analysis data are used to calculate diverse kinematic, thermodynamic, and hybrid metrics, all of which are analyzed for their ability to differentiate between storm stages and the degree of organization using nonparametric statistical inferences.

Results show that $\mathrm{CAPE}_{11}$ is the most effective metric for diagnosing the maintenance of the MCSs under consideration, providing strong evidence for the fundamental importance of layer-lifting convective instability. For instance, interstage $\mathrm{CAPE}_{11}$ reductions represent the most reliable means for identifying storm dissipation, as exemplified by an informal evaluation of metric performance with a simple MCS dissipation-forecasting model. In addition, $\mathrm{CAPE}_{1 \mathrm{l}}$ stands out as the most capable discriminator between mature and dissipating systems, demonstrating its usefulness for diagnosing MCS stage. These results are complemented by an analysis based on C17's categorization by the degree of organization, suggesting a strong link between $\mathrm{CAPE}_{11}$ reductions and system disorganization at dissipation. Additionally, Corfidi vectors are shown to be useful for accurately approximating $\mathrm{CAPE}_{\mathrm{ll}}$, providing a potentially valuable metric in forecasting applications.
Among other findings that lend weight to the layerlifting conceptual model, ICAPE consistently outperforms other thermodynamic metrics, in agreement with the importance of the latent heating experienced by all convectively unstable parcels. Additionally, in all statistical tests considered herein, the ordering of $\mathrm{CAPE}_{\mathrm{ll}}$, ICAPE, and MLCAPE/MUCAPE by their performance (decreasing from first to last) coincides with what would be expected from layer-lifting arguments. Furthermore, the inflow fraction of low-tropospheric air, which measures the dilution of latent heating due to inflowing air at midlevels, is the most skillful kinematic index for determining MCS stage and stage transition. These results indicate that both kinematic and thermodynamic effects contribute significantly to enhance the performance of $\mathrm{CAPE}_{\mathrm{ll}}$, as the latter is shown to be well approximated by an expression proportional to the product of ICAPE and the inflow fraction.

The layer-lifting framework is also used to explain the association between certain environmental factors and MCS organization and maintenance. For instance, the frequent observation that severe and highly organized MCSs occur in dry midtropospheric environments (e.g., Wakimoto 2001; Corfidi 2003; James et al. 2006; Cohen et al. 2007) is partly attributed to the accompanying steep temperature lapse rates of elevated air from the Mexican Plateau and the Rocky Mountains, as such temperature profiles support greater ICAPE (e.g., AK). The relationship between midlevel inflow and MCS maintenance and organization, also documented by Evans and Doswell (2001) and CBWC, can be explained through the inflow fraction, wherein weaker midtropospheric inflow produces less dilution, favoring 


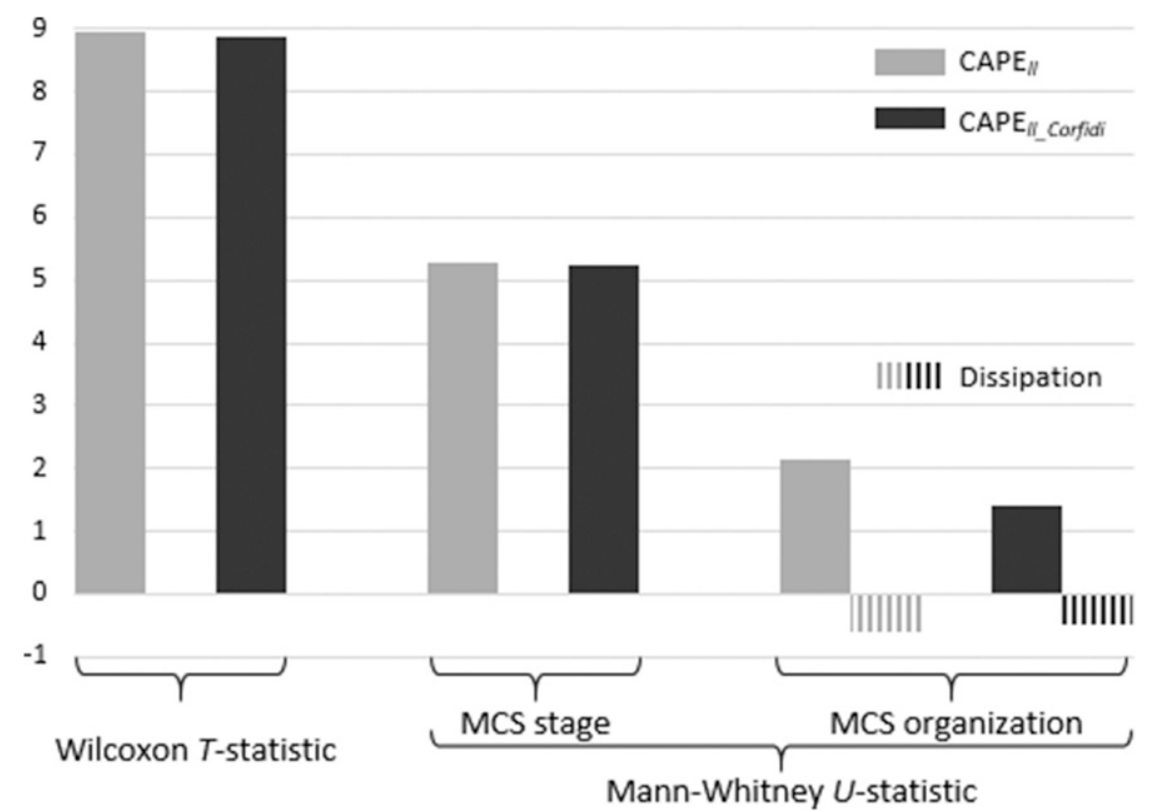

FIG. 11. The CAPE $\mathrm{Il}_{11}$ and $\mathrm{CAPE}_{\mathrm{ll} \_ \text {Corfidi }} Z$ scores for the three statistical inferences, as indicated at the bottom.

storm maintenance and severity. This reasoning also applies to the low-tropospheric shear, as storms in environments with weak shear at low levels tend to produce greater midtropospheric inflow (see A17). However, it is acknowledged that dynamic factors other than those pertaining to convective instability can have a strong impact on MCS organization and maintenance (e.g., Parker and Johnson 2004), while not all thermodynamic impacts can be explained via layer-lifting arguments [e.g., the relatively large (small) skill of near-surface temperature lapse rates (CAPE indices) for diagnosing system organization]. Thus, a more detailed analysis is needed to make a precise attribution of different effects on MCS maintenance.

Limitations regarding the applicability of this study's results are also worth discussing. For example, only forward-propagating severe-wind-producing MCSs were considered, and there is no guarantee that similar results would be obtained for more general systems. Also, given that many thermodynamic and kinematic environmental features vary systematically in association with MCS dissipation, interpretations can be obscured by significant correlations between different metrics. This is exemplified by cases described in the previous paragraph, for example, moisture and lapse rates aloft, as well as low-tropospheric shear and midtropospheric inflow. In relation to operational applications, considering that this study is mainly concerned with determining the relevance of layer-lifting effects for MCS maintenance, formulations and formal evaluations of forecasting models using layer-lifting metrics remain to be done. Regardless of these limitations, we consider that this study merits the application and further development of layer-lifting concepts.

Acknowledgments. This paper benefited from detailed reviews by Editor Matthew J. Bunkers and three anonymous reviewers. This study was partially funded by the PAPIIT program of UNAM under Grant IN-104416. DAA benefited from the postdoctoral fellowship and SIJA programs sponsored by DGAPAUNAM. Much of the MCS dataset was compiled with support from National Science Foundation Grant AGS-1062932, and NOAA/Office of Oceanic and Atmospheric Research under NOAA/University of Oklahoma Cooperative Agreement NA11OAR4320072, U.S. Department of Commerce.

\section{REFERENCES}

Alfaro, D. A., 2017: Low-tropospheric shear in the structure of squall lines: Impacts on latent heating under layer-lifting ascent. J. Atmos. Sci., 74, 229-248, https://doi.org/10.1175/ JAS-D-16-0168.1.

— , and M. Khairoutdinov, 2015: Thermodynamic constraints on the morphology of simulated midlatitude squall lines. J. Atmos. Sci., 72, 3116-3137, https://doi.org/10.1175/JAS-D-14-0295.1.

Ashley, W. S., and T. L. Mote, 2005: Derecho hazards in the United States. Bull. Amer. Meteor. Soc., 86, 1577-1592, https:// doi.org/10.1175/BAMS-86-11-1577. 
Benjamin, S. G., and Coauthors, 2004: An hourly assimilationforecast cycle: The RUC. Mon. Wea. Rev., 132, 495-518, https:// doi.org/10.1175/1520-0493(2004)132<0495:AHACTR>2.0.CO;2.

_, and Coauthors, 2016: A North American hourly assimilation and model forecast cycle: The Rapid Refresh. Mon. Wea. Rev., 144, 1669-1694, https://doi.org/10.1175/MWR-D-15-0242.1.

Bluestein, H. B., and M. H. Jain, 1985: Formation of mesoscale lines of precipitation: Severe squall lines in Oklahoma during the spring. J. Atmos. Sci., 42, 1711-1732, https://doi.org/ 10.1175/1520-0469(1985)042<1711:FOMLOP > 2.0.CO;2.

Bonner, W. D., 1968: Climatology of the low level jet. Mon. Wea. Rev., 96, 833-850, https://doi.org/10.1175/1520-0493(1968) 096<0833:COTLLJ $>2.0$.CO;2.

Bryan, G. H., and M. J. Fritsch, 2000: Moist absolute instability: The sixth static stability state. Bull. Amer. Meteor. Soc., 81, 1207-1230, https://doi.org/10.1175/1520-0477(2000)081<1287: MAITSS $>2.3 . \mathrm{CO} ; 2$.

, D. Ahijevych, C. Davis, S. Trier, and M. Weisman, 2005: Observations of cold pool properties in mesoscale convective systems during BAMEX. 11th Conf. on Mesoscale Processes/ 32nd Conf. on Radar Meteorology, Albuquerque, NM, Amer. Meteor. Soc., JP5J, https://ams.confex.com/ams/pdfpapers/ 96718.pdf.

— J. C. Knievel, and M. D. Parker, 2006: A multimodel assessment of RKW theory's relevance to squall-line characteristics. Mon. Wea. Rev., 134, 2772-2792, https://doi.org/ 10.1175/MWR3226.1.

Bunkers, M. J., B. A. Klimowski, and J. W. Zeitler, 2002: The importance of parcel choice and the measure of vertical wind shear in evaluating the convective environment. 21st Conf. on Severe Local Storms, San Antonio, TX, Amer. Meteor. Soc., P8.2, https://ams.confex.com/ams/pdfpapers/47319.pdf.

Campbell, M. A., A. E. Cohen, M. C. Coniglio, A. R. Dean, S. F. Corfidi, S. J. Corfidi, and C. M. Mead, 2017: Structure and motion of severe-wind-producing mesoscale convective systems and derechos in relation to the mean wind. Wea. Forecasting, 32, 423-439, https://doi.org/10.1175/WAF-D-16-0060.1.

Carlson, T. N., S. G. Benjamin, G. S. Forbes, and Y. F. Li, 1983: Elevated mixed layers in the regional severe storm environment: Conceptual model and case studies. Mon. Wea. Rev., 111, 1453-1474, https://doi.org/10.1175/1520-0493(1983) 111<1453:EMLITR>2.0.CO;2.

Cohen, A. E., M. C. Coniglio, S. F. Corfidi, and S. J. Corfidi, 2007: Discrimination of mesoscale convective system environments using sounding observations. Wea. Forecasting, 22, 1045-1062, https://doi.org/10.1175/WAF1040.1.

Coniglio, M. C., 2012: Verification of RUC 0-1-h forecasts and SPC mesoscale analyses using VORTEX2 soundings. Wea. Forecasting, 27, 667-683, https://doi.org/10.1175/WAF-D-11-00096.1.

, D. J. Stensrud, and M. B. Richman, 2004: An observational study of derecho-producing convective systems. Wea. Forecasting, 19, 320-337, https://doi.org/10.1175/1520-0434(2004) $019<0320$ :AOSODC $>2.0 . \mathrm{CO} ; 2$.

,-- , and L. J. Wicker, 2006: Effects of upper-level shear on the structure and maintenance of strong quasi-linear mesoscale convective systems. J. Atmos. Sci., 63, 1231-1252, https:// doi.org/10.1175/JAS3681.1.

, H. E. Brooks, S. J. Weiss, and S. F. Corfidi, 2007: Forecasting the maintenance of quasi-linear mesoscale convective systems. Wea. Forecasting, 22, 556-570, https://doi.org/10.1175/ WAF1006.1.

_ J. Y. Hwang, and D. J. Stensrud, 2010: Environmental factors in the upscale growth and longevity of MCSs derived from
Rapid Update Cycle analyses. Mon. Wea. Rev., 138, 3514 3539, https://doi.org/10.1175/2010MWR3233.1.

_ S. F. Corfidi, and J. S. Kain, 2012: Views on applying RKW theory: An illustration using the 8 May 2009 derechoproducing convective system. Mon. Wea. Rev., 140, 10231043, https://doi.org/10.1175/MWR-D-11-00026.1.

Corfidi, S. F., 2003: Cold pools and MCS propagation: Forecasting the motion of downwind-developing MCSs. Wea. Forecasting, 18, 997-1017, https://doi.org/10.1175/1520-0434(2003)018<0997: CPAMPF $>2.0 . \mathrm{CO} ; 2$.

—, M. C. Coniglio, A. E. Cohen, and C. M. Mead, 2016: A proposed revision to the definition of "derecho." Bull. Amer. Meteor. Soc., 97, 935-949, https://doi.org/10.1175/BAMS-D-14-00254.1.

Doswell, C. A., III, H. E. Brooks, and R. A. Maddox, 1996: Flash flood forecasting: An ingredients-based methodology. Wea. Forecasting, 11, 560-581, https://doi.org/10.1175/ 1520-0434(1996)011<0560:FFFAIB > 2.0.CO;2.

Durran, D. R., and J. A. Weyn, 2016: Thunderstorms do not get butterflies. Bull. Amer. Meteor. Soc., 97, 237-243, https:// doi.org/10.1175/BAMS-D-15-00070.1.

Evans, J. S., and C. A. Doswell III, 2001: Examination of derecho environments using proximity soundings. Wea. Forecasting, 16, 329-342, https://doi.org/10.1175/1520-0434(2001)016<0329: EODEUP $>2.0 . \mathrm{CO} ; 2$.

Fritsch, J. M., R. J. Kane, and C. R. Chelius, 1986: The contribution of mesoscale convective weather systems to the warm-season precipitation in the United States. J. Climate Appl. Meteor., 25, 1333-1345, https://doi.org/10.1175/1520-0450(1986)025<1333: TCOMCW $>2.0 . C O ; 2$.

Gale, J. J., W. A. Gallus Jr., and K. A. Jungbluth, 2002: Toward improved prediction of mesoscale convective system dissipation. Wea. Forecasting, 17, 856-872, https://doi.org/10.1175/ 1520-0434(2002)017<0856:TIPOMC $>2.0 . C O ; 2$.

Houze, R. A., Jr., 2004: Mesoscale convective systems. Rev. Geophys., 42, RG4003, doi:10.1029/2004RG000150.

James, R. P., P. M. Markowski, and J. M. Fritsch, 2006: Bow echo sensitivity to ambient moisture and cold pool strength. Mon. Wea. Rev., 134, 950-964, https://doi.org/10.1175/MWR3109.1.

Jirak, I. L., and W. R. Cotton, 2007: Observational analysis of the predictability of mesoscale convective systems. Wea. Forecasting, 22, 813-838, https://doi.org/10.1175/WAF1012.1.

—,$\ldots$, and R. L. McAnelly, 2003: Satellite and radar survey of mesoscale convective system development. Mon. Wea. Rev., 131, 2428-2449, https://doi.org/10.1175/1520-0493(2003)131<2428: SARSOM $>2.0 . \mathrm{CO} ; 2$.

Johns, R. H., and W. D. Hirt, 1987: Derechos: Widespread convectively induced windstorms. Wea. Forecasting, 2, 32-49, https:// doi.org/10.1175/1520-0434(1987)002<0032:DWCIW>2.0.CO;2.

Kingsmill, D. E., and R. A. Houze Jr., 1999: Kinematic characteristics of air flowing into and out of precipitating convection over the west Pacific warm pool: An airborne Doppler radar survey. Quart. J. Roy. Meteor. Soc., 125, 1165-1207, https://doi.org/10.1002/qj.1999.49712555605.

Letkewicz, C. E., and M. D. Parker, 2010: Forecasting the maintenance of mesoscale convective systems crossing the Appalachian Mountains. Wea. Forecasting, 25, 1179-1195, https:// doi.org/10.1175/2010WAF2222379.1.

Maddox, R. A., C. F. Chappell, and L. R. Hoxit, 1979: Synoptic and meso- $\alpha$ scale aspects of flash flood events. Bull. Amer. Meteor. Soc., 60, 115-123, https://doi.org/10.1175/1520-0477-60.2.115.

Mahoney, K. M., G. M. Lackmann, and M. D. Parker, 2009: The role of momentum transport in the motion of a quasi-idealized mesoscale convective system. Mon. Wea. Rev., 137, 3316-3338, https://doi.org/10.1175/2009MWR2895.1. 
Mapes, B. E., 1993: Gregarious tropical convection. J. Atmos. Sci., 50, 2026-2037, https://doi.org/10.1175/1520-0469(1993)050<2026: GTC $>2.0 . C O ; 2$.

Mechem, D. B., R. A. Houze Jr., and S. S. Chen, 2002: Layer inflow into precipitating convection over the western tropical Pacific. Quart. J. Roy. Meteor. Soc., 128, 1997-2030, https://doi.org/ 10.1256/003590002320603502.

Melhauser, C., and F. Zhang, 2012: Practical and intrinsic predictability of severe and convective weather at the mesoscales. J. Atmos. Sci. 69, 3350-3371, https://doi.org/10.1175/JAS-D-11-0315.1.

Moncrieff, M. W., 2010: The multiscale organization of moist convection and the intersection of weather and climate. Climate Dynamics: Why Does Climate Vary?, D.-Z. Sun and F. Bryan, Eds., John Wiley and Sons, 3-26, https://doi.org/ 10.1029/2008GM000838.

NCEI, 2017: National Radar Reflectivity Mosaic. National Centers for Environmental Information, https:/gis.ncdc.noaa.gov/ maps/ncei/radar.

Nicholls, M. E., R. H. Johnson, and W. R. Cotton, 1988: The sensitivity of two-dimensional simulations of tropical squall lines to environmental profiles. J. Atmos. Sci., 45, 3625-3649, https://doi.org/ 10.1175/1520-0469(1988)045<3625:TSOTDS > 2.0.CO;2.

Nielsen, E. R., and R. S. Schumacher, 2016: Using convectionallowing ensembles to understand the predictability of an extreme rainfall event. Mon. Wea. Rev., 144, 3651-3676, https://doi.org/10.1175/MWR-D-16-0083.1.

Orlanski, I., 1975: A rational subdivision of scales for atmospheric processes. Bull. Amer. Meteor. Soc., 56, 527-530.

Parker, M. D., and R. H. Johnson, 2000: Organizational modes of midlatitude mesoscale convective systems. Mon. Wea. Rev. 128,3413-3436, https://doi.org/10.1175/1520-0493(2001)129<3413: OMOMMC $>2.0 . \mathrm{CO} ; 2$.

— and - 2004: Structures and dynamics of quasi-2D mesoscale convective systems. J. Atmos. Sci., 61, 545-567, https:// doi.org/10.1175/1520-0469(2004)061<0545:SADOQM>2.0.CO;2.

Peters, J. M., E. R. Nielsen, M. D. Parker, S. M. Hitchcock, and R. S. Schumacher, 2017: The impact of low-level moisture errors on model forecasts of an MCS observed during PECAN. Mon. Wea. Rev., 145, 3599-3624, https://doi.org/ 10.1175/MWR-D-16-0296.1.

Rotunno, R., J. B. Klemp, and M. L. Weisman, 1988: A theory for strong, long-lived squall lines. J. Atmos. Sci., 45, 463-485, https://doi.org/10.1175/1520-0469(1988)045<0463: ATFSLL $>2.0 . \mathrm{CO} ; 2$.

Schultz, D. M., and P. N. Schumacher, 1999: The use and misuse of conditional symmetric instability. Mon. Wea. Rev., 127, 2709-2732, https://doi.org/10.1175/1520-0493(1999)127<2709: TUAMOC $>2.0 . \mathrm{CO} ; 2$.
Schumacher, R. S., and R. H. Johnson, 2005: Organization and environmental properties of extreme-rain-producing mesoscale convective systems. Mon. Wea. Rev., 133, 961976, https://doi.org/10.1175/MWR2899.1.

, and —, 2009: Quasi-stationary, extreme-rain-producing convective systems associated with midlevel cyclonic circulations. Wea. Forecasting, 24, 555-574, https://doi.org/10.1175/ 2008WAF2222173.1.

Stensrud, D. J., M. C. Coniglio, R. P. Davies-Jones, and J. S. Evans, 2005: Comments on "A theory for strong long-lived squall lines' revisited.”' J. Atmos. Sci., 62, 2989-2996, https://doi.org/ 10.1175/JAS3514.1.

Takemi, T., 2006: Impacts of moisture profile on the evolution and organization of midlatitude squall lines under various shear conditions. Atmos. Res., 82, 37-54, https://doi.org/ 10.1016/j.atmosres.2005.01.007.

Thompson, R. L., R. Edwards, J. A. Hart, K. L. Elmore, and P. Markowski, 2003: Close proximity soundings within supercell environments obtained from the Rapid Update Cycle. Wea. Forecasting, 18, 1243-1261, https://doi.org/10.1175/ 1520-0434(2003)018<1243:CPSWSE > 2.0.CO;2.

Thorpe, A. J., M. J. Miller, and M. W. Moncrieff, 1982: Twodimensional convection in non-constant shear: A model of mid-latitude squall lines. Quart. J. Roy. Meteor. Soc., 108, 739-762, https://doi.org/10.1002/qj.49710845802.

Wakimoto, R. M., 2001: Convectively driven high wind events. Severe Convective Storms, Meteor. Monogr., No. 50, Amer. Meteor. Soc., 255-298.

Wandishin, M. S., D. J. Stensrud, S. L. Mullen, and L. J. Wicker, 2010: On the predictability of mesoscale convective systems: Three-dimensional simulations. Mon. Wea. Rev., 138, 863-885, https://doi.org/10.1175/2009MWR2961.1.

Weisman, M. L., 1992: The role of convectively generated rearinflow jets in the evolution of long-lived mesoconvective systems. J. Atmos. Sci., 49, 1826-1847, https://doi.org/10.1175/ 1520-0469(1992)049<1826:TROCGR > 2.0.CO;2.

1993: The genesis of severe, long-lived bow echoes. J. Atmos. Sci., 50, 645-670, https://doi.org/10.1175/1520-0469(1993)050<0645: TGOSLL $>2.0 . \mathrm{CO} ; 2$

— , and R. Rotunno, 2004: "A theory for strong long-lived squall lines" revisited. J. Atmos. Sci., 61, 361-382, https://doi.org/ 10.1175/1520-0469(2004)061<0361:ATFSLS > 2.0.CO;2.

Weyn, J. A., and D. R. Durran, 2017: The dependence of the predictability of mesoscale convective systems on the horizontal scale and amplitude of initial errors in idealized simulations. J. Atmos. Sci., 74, 2191-2210, https://doi.org/10.1175/JAS-D-17-0006.1.

Wilks, D. S., 2006: Statistical Methods in the Atmospheric Sciences. Academic Press, 648 pp. 